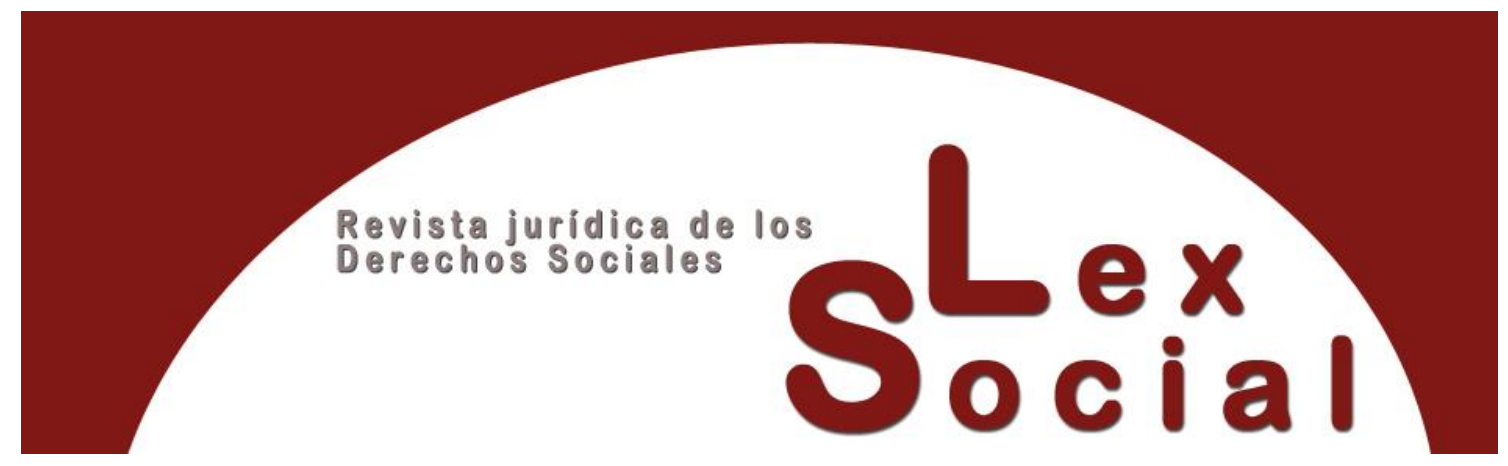

\title{
EL DERECHO A LA FORMACIÓN Y A LA CUALIFICACIÓN PROFESIONAL EN EL EMPLEO DOMÉSTICO
}

\section{THE RIGHT TO TRAINING AND TO PROFESSIONAL QUALIFICATION IN DOMESTIC WORK}

\author{
CARMEN GRAU PINEDA ${ }^{1}$ \\ Titular de Universidad Derecho del Trabajo y Seguridad Social \\ Universidad de Las Palmas de Gran Canaria \\ https://orcid.org/0000-0003-0274-8875
}

Cómo citar este trabajo: Grau Pineda, Carmen (2021). El derecho a la formación y a la cualificación profesional en el empleo doméstico. Lex Social: Revista De Derechos Sociales, 11 (1), 474-508. https://doi.org/10.46661/lexsocial.5425

\section{RESUMEN}

Que el tema del empleo doméstico este últimamente de moda no es en modo alguno casual. Múltiples son las variables que han influido en ello, pero es fácil entender que con la incorporación masiva de las mujeres al mercado de trabajo haya sido preciso redistribuir las tareas y cuidados intrafamiliares entre los miembros de cada unidad familiar o "externalizarlos" y acudir a la prestación de servicios por personas ajenas a la misma. En este contexto general, es de gran utilidad revisar el papel que la formación y cualificación profesional tiene en la dignificación, valorización y, por tanto, visibilización

\footnotetext{
${ }^{1}$ ResearchID: N-9223-2014. Este trabajo se encuadra en las actividades del Laboratorio de Derecho Social, línea de estudio Trabajo Doméstico y del Seminario Permanente de Trabajo Doméstico de la UC3M, Proyecto subvencionado en la convocatoria 2019, IMIO, 12/4ACT, ambos dirigidos por la profesora $\mathrm{M}^{\mathrm{a}}$. Gema Quintero Lima. Es éste el resultado definitivo, actualizado y cerrado de una investigación que se tuvo la oportunidad de, primero, divulgar en la plataforma The Conversation (https://theconversation.com/empleo-domestico-igualdad-y-formacion-profesional-139065) y, segundo, presentar y exponer en formato póster en el III Congreso Mundial CIELO LABORAL «Quel Rôle pour les entreprises, les travailleur, les organisations représentatives, les citoyens et les États dans le Droit du travail et de la protection sociale du 21ème siècle?», 24-25 septiembre de 2020 (https://cielo2020.sciencesconf.org/resource/page/id/31).
} 
de este trabajo, de este sector y de un colectivo de trabajadoras vulnerables como pocos. Y, para llevar a cabo tal labor, ha decidido estructurarse esta aportación intentando dar respuesta a tres preguntas concretas: ¿Por qué es el sector de empleo doméstico un sector emergente?, ¿existe un derecho laboral a la formación profesional para este colectivo?, ¿de qué formación se dispone, por qué no se demuestra eficaz y quién es el responsable de ello?

Palabras Clave: empleo doméstico, trabajadoras domésticas, hogar familiar, cuidados, formación y cualificación.

\begin{abstract}
That the issue of domestic work is lately in fashion is by no means casual. There are multiple variables that have influenced this, but it is easy to understand that with the massive incorporation of women into the labor market it has been necessary to redistribute tasks and intrafamily care among the members of each family unit or to "outsource" them and go to the provision of services by outsiders. In this general context, it is important to review the role that professional training and qualification has in the dignity, valorization and, therefore, visibility of this work, of this sector and of a group of vulnerable workers as few. And, to carry out this work, it has decided to structure this contribution trying to answer three specific questions: Why is the sector an emerging sector of domestic employment? Is there a labor right to vocational training? What training is available, why is it not given importance and who does not?
\end{abstract}

KeYWORDS: domestic service, domestic workers, family home, care, training and qualification.

\title{
SUMARIO
}

\section{Algunas consideraciones previas.}

II. Tres cuestiones fundamentales por abordar en la materia.

1. ¿Por qué es un sector productivo emergente?. Principales razones.

2. ¿Existe un derecho laboral a la formación profesional para este colectivo?.

3. Las tres W: What, why and who?: ¿De qué formación se dispone?, ¿por qué no se le da importancia a la formación de las personas trabajadoras en este sector? y ¿quién no lo hace?.

3. 1. ¿De qué formación se dispone? Una radiografía de la oferta formativa existente.

3.1.1. La Formación Profesional inicial específica: el ciclo formativo de formación profesional básica en actividades domésticas y limpieza de edificios. 
3.1.2. La Formación Profesional para el empleo especifica: el certificado de profesional para el empleo doméstico.

3.2. ¿Por qué no se demuestra eficaz este sistema y quién es el responsable de ello?: la importancia del fomento del asociacionismo y la sindicación en el sector.

\subsubsection{Problemas de representación sindical y/o empresarial}

3.2.2. Problemas derivados de la prioridad de otros aspectos diferentes a los formativos que se consideran preferentes: prevención de riesgos laborales y desempleo

III. Algunas ideas conclusivas.

Bibliografía.

Anexo.

\section{Algunas consideraciones preliminares}

Que el tema del trabajo doméstico este últimamente de moda no es en modo alguno casual. Múltiples son las variables que han influido en ello, pero es fácil entender que con la incorporación masiva de las mujeres al mercado de trabajo haya sido preciso redistribuir las tareas y cuidados intrafamiliares entre los miembros de cada unidad familiar o "externalizarlos" y acudir a la prestación de servicios por personas ajenas a la misma $^{2}$. Se constata cómo mientras unas mujeres han salido de sus hogares al mercado, otras han entrado en los hogares de las primeras para suplir su falta de dedicación a tareas y cuidados que siguen estando en manos de mujeres, pese al gradual aumento de las corresponsabilidad en las generaciones más jóvenes, siguen estando infravaloradas y siguen teniendo la consideración de trabajo "altruista", "generoso" y, por tanto, sin valor económico.

Pero es que, además, y por si fuera poco, es uno de los colectivos que precisa progresar en su regulación y protección por ostentar una condición de extrema vulnerabilidad, como de hecho se ha puesto de manifiesto durante la crisis sanitaria del COVID-19 ${ }^{3}$. Y, en este contexto general, es de gran utilidad revisar el papel que la formación y cualificación profesional tiene en la dignificación, valorización y, por tanto, visibilización de este trabajo, de este sector y de un colectivo de trabajadoras vulnerables como pocos en el que, es frecuente además, confluyan causas diversas de discriminación y/o vulnerabilidad social (mujeres, mayores, inmigrantes).

\footnotetext{
${ }^{2}$ En ese contexto hay una -llámese- laguna de sujetos responsables del cuidado en los hogares. Momento en el que se activa la maniobra de descentralización/ externalización de la responsabilidad del cuidado. Y el trabajo de servicio doméstico resulta ser, en sus distintas formas, el modo de conciliar el cuidado del hogar y sus miembros, y la vida laboral. Más detalles en QUINTERO LIMA, Ma . Gema, "El trabajo de servicio doméstico como una realidad jurídica inevitable", Revista jurídica de los Derechos Sociales Lex Social, 2019, vol. 9, nº 2, p. 5.

3 SALCEDO BELTRÁN, Carmen, "El trabajo doméstico en España: planteamientos y desafíos insoslayables frente a la "esclavitud moderna", Revista General de DTSS, Iustel, 2020, no 55, p. 2.
} 
Y, para llevar a cabo tal labor, ha decidido estructurarse esta aportación intentando dar respuesta a tres preguntas concretas: ¿Por qué es el sector de empleo doméstico un sector emergente?, ¿existe un derecho laboral a la formación profesional?, ¿de qué formación se dispone, por qué no se le da importancia y quién no lo hace?.

\section{Tres cuestiones fundamentales por abordar en la materia.}

\section{1. ¿Por qué es un sector productivo emergente?. Principales razones.}

Las grandes cifras arrojan como resultado que el mundo hay 67 millones de personas trabajadoras en el sector del empleo doméstico, 21 millones en la UE-27 con un aumento constante en las últimas dos décadas de casi un $25 \%$ desde principios de este Siglo ${ }^{4}$.

En España este sector casi cuadriplica la media de la UE- $28^{5}$ en donde la mayoría de los países se sitúan en una proporción de empleo doméstico inferior o próxima al 1\%, mientras en España (también en Italia y Chipre y seguidos muy de cerca por Portugal) se habla de cifras que oscilan entre 3-4\%. Según datos del Observatorio de las ocupaciones (SEPE) para el año 2019, si bien solo poco más del 50\% (53.53\%) de las mujeres están activas e incorporadas al mercado de trabajo (ocupadas $-45.21 \%$ - o paradas $-15.55 \%$-), cerca de un $70 \%$ del total de las mujeres activas se dedican al sector servicios (terciarización del empleo femenino), del que casi un $20 \%$ lo hacen en servicios, restauración y comercio, y dentro de este epígrafe, un $10 \%$ lo hace, en concreto, como personal de limpieza.

Pero es que si miramos los datos de afiliación, resulta que de las quince primeras actividades económicas con mayor número de afiliadas hay casi 400.000 mujeres $^{6}$ que según consta se dedican a las actividades de los hogares como empleadores de personal doméstico $(89.37 \% \text { tasa de mujeres })^{7}$.

La tendencia de la incorporación de las mujeres al mercado de trabajo es ascendente y constante en los últimos años, siendo el empleo doméstico el cuarto con una variación interanual positiva (2.23\%) -solo por detrás de teleoperadores (la ocupación que más crece con diferencia), peones en obras públicas y albañiles- y con un fuerte impacto en el colectivo de mujeres. Colectivo que acapara en lo referido a los cuidados personales/de niños en domicilios (SEPE, julio 2020) más del 95\% de los parados demandantes de empleo mujeres y similares porcentajes de contrato celebrados por mujeres.

\footnotetext{
${ }^{4}$ CEDEFOP, "Quality assurance in the social care sector, research paper. The role of training", $\mathrm{n}^{\mathrm{o}} 7,2010$, disponible en https://www.cedefop.europa.eu/en/publications-and-resources/publications/5507

${ }^{5}$ Comentario en el Blog especializado FORO DE LABOS "El trabajo al servicio del hogar: algunas propuestas desde el proyecto europeo PHS-QUALITY" a cargo de GÓMEZ ABELLEIRA, Francisco Javier el 10.07.2020. Disponible en https://forodelabos.blogspot.com/2020/07/el-trabajo-al-servicio-delhogar.html

${ }^{6}$ En concreto, 391.486, con un total de 193.692 contratos celebrados ( $87.92 \%$ tasa mujeres), la gran mayoría con mujeres mayores de 25 años y una tasa de estabilidad de un $45 \%$.

${ }^{7}$ Las cinco primeras son, por este orden, comercio al por menor, actividades sanitarias, educaciones, servicios de comidas y bebidas y administración pública y defensa.
} 
Las razones son obvias: aumento de las necesidades externas de prestación de servicios (tareas y cuidados intrafamiliares) que, hasta hace poco tiempo, eran prestados de forma altruista e innata por las mujeres que, ahora en una coyuntura social y económica propicia, salen al mercado de trabajo para ser independientes económicamente de sus parejas y realizarse como profesionales (normalmente, tras haber tenido acceso a estudios medios y superiores). Y ese déficit tiende a ser o bien compartido en el seno intrafamiliar o bien "externalizado" y suplido por otras mujeres ajenas al núcleo familiar y que sea por la carencia de estudios, por el origen racial o social, o por las razones que fuere no pueden acceder al tipo de trabajas o empleos al que acceden las primeras. Se polariza el colectivo femenino entre las primeras y las segundas que se ven inmersas en un círculo perverso en el que los varones no participan por mantenerse, en general, ajenos a tales labores. Se polariza pero en ambos polos se perpetúan las dificultades referidas al género porque las que deciden "salir" se enfrentan a todo tipo de obstáculos y dificultades que no han de afrontar sus compañeros; y las que "suplen" siguen siendo invisibles como lo fueran las primeras antes de salir y sus madres y sus abuelas...

Los cambios sociales han llevado a una necesidad mucho mayor de servicios de atención, especialmente para los más vulnerables -niños, discapacitados y mayores, y allá donde no llegan los servicios públicos, son las familias (lo privado) las que deben buscar las mejores opciones referidas a la prestación pública y/o privada de estos servicios en el mercado. De ahí que se sostenga estar en presencia de un "nicho de empleo", de un sector emergente y en clara expansión. Sin embargo, el principal hándicap es que este sector productivo sigue careciendo de personal cualificado por tratarse de servicios casi exclusivamente femeninos y, por tanto, infravalorados. De ahí que se considere fundamental que el sector se oriente más y mejor a la demanda que se le hace y sea más eficaz en esa labor de "casamiento" entre oferta y demanda y, para ello, es fundamental que las personas trabajadoras estén formadas y cualificadas para desempeñar estos servicios, cuenten con competencias genéricas referidas al contenido de los servicios a prestar, más allá de las habilidades específicas o especializadas que puedan demandarse ${ }^{8}$.

Repárese en el hecho de que las distintas opciones posibles responden a tres modelos imperantes en Europa, como ya se adelantó al hablar de los cuidadores no profesionales ${ }^{9}$ :

1. El modelo liberal, con Reino Unido como país de referencia, se recurre a las mujeres inmigrantes, pero no contratadas directamente por las familias, sino por centros o agencias especializadas ${ }^{10}$, que ocupan estos puestos únicamente si están regularizadas

\footnotetext{
${ }^{8}$ Las personas trabajadoras del sector necesitan competencias especificas (limpieza, planchado o cocina) pero también básicas como las competencias sociales o habilidades interpersonales, por no hablar de las "habilidades verdes" en el marco de la economía sostenible.

${ }^{9}$ Vid. GRAU PINEDA, Carmen, "Empleo doméstico y cuidadores informales: obstáculos para conciliar", en VVAA: Reflexiones sobre el empleo doméstico: De dónde venimos, dónde nos encontramos y hacia dónde vamos, Servicio Central de Publicaciones del Gobierno Vasco, 2020, pp. 103-122.

${ }^{10}$ Muy criticadas, pese a levantarse el veto legal en torno a ellas con la aprobación del Convenio 181 OIT, porque de su actuación, bastante marginal en general, se derivan serias dudas de explotación dado que estamos ante un sector en el que han prevalecido los sistemas privados e informales de búsqueda de empleo, faltos de control y garantías para las personas trabajadoras.
} 
y tienen una formación profesional acreditada, teniendo acceso a los mismos y permaneciendo en ellos por las reticencias de las mujeres autóctonas a desempeñarlos dadas las duras condiciones de trabajo y el escaso prestigio social.

2. El modelo socialdemócrata, como es el caso de Holanda, las familias no tienen necesidad de recurrir a las trabajadoras inmigrantes por la existencia de una amplia oferta de servicios públicos. Pero es que, además, es muy difícil para ellas acceder a estos puestos porque se exige cualificación y especialización, constituyendo nichos de empleo atractivos para las mujeres autóctonas ${ }^{11}$.

3. Finalmente, el modelo mediterráneo, propio de países como Italia, Grecia y España, presenta dos rasgos fundamentales: un gasto reducido en servicios de atención a la dependencia y una importante proporción de inmigrantes en puestos de trabajo no cualificados, a los que se les une la extensión de la economía sumergida y del empleo irregular con la aceptación social de todas las facetas derivadas de estas prácticas (cifrado en España de en torno al $70 \%{ }^{12}$ ).

Este último modelo, el nuestro, el trabajo doméstico se considera un sustituto de la atención institucional. $\mathrm{Y}$ es que en un sector como éste caracterizado por la escasa implicación de las administraciones públicas (frente a las otras dos opciones muchos más institucionalizadas) y la ausencia de una respuesta eficaz por parte del mercado privado, las familias se ven impulsadas a buscar otras alternativas a través de la contratación informal de mujeres, en muchos casos, inmigrantes que, a menor coste y con gran disponibilidad, están dispuestas a realizar trabajos rechazados por las mujeres autóctonas ${ }^{13}$. De todo ello, puede colegirse que ha sido la presencia de mujeres inmigrantes la que ha terminado por consolidar, por tanto, la "feminización" del sector en ambos lados de la relación laboral. Es decir, "aunque parte de las actividades domésticas

\footnotetext{
${ }^{11}$ Pero es que, en adición a lo anterior, el elevado control existente sobre las prestaciones económicas que reciben las familias hace aún más complicado destinarlo a la contratación de un perfil de persona trabajadora que no cumple con los requisitos que el marco regulador exige para este tipo de actividad.

${ }^{12}$ EFSI, PHS Industry Monitor, Statistical overview of the personal and household services secteur in the European Union, April 2018, p. 22, disponible en http://www.efsieurope.eu/fileadmin/MEDIA/publications/2018/PHS_Industry_monitor_April_2018.pdf

${ }^{13}$ Es importante señalar que este tipo de trabajos no se encuentra en el catálogo de ocupaciones de difícil cobertura que es el que contiene aquellas profesiones cuyas ofertas de empleo son más difíciles de gestionar a la hora de cubrir puestos vacantes. El catálogo, al que se alude en el artículo 65.1 del Real Decreto 557/2011, de 20 de abril, por el que se aprueba el Reglamento de la Ley Orgánica 4/2000, sobre derechos y libertades de los extranjeros en España y su integración social, tras su reforma por Ley Orgánica 2/2009, contiene las ocupaciones en las que los Servicios Públicos de Empleo han encontrado dificultad para gestionar las ofertas de empleo que los empleadores les presentan cuando quieren cubrir puestos de trabajo vacantes. Se elaborará para cada provincia, islas en el caso de las provincias insulares y para las ciudades autónomas de Ceuta y Melilla; tiene carácter trimestral, extendiéndose su vigencia desde el primer hasta el último día laborable del trimestre natural siguiente al de su publicación; y la presencia de una ocupación en el catálogo de la zona geográfica de que se trate, implica, para el empleador, la posibilidad de tramitar la autorización para residir y trabajar dirigida a un trabajador extranjero. Y esto es importante tenerlo en cuenta porque de no encontrarse referencia alguna al empleo domestico en dicho catálogo, o podrá solicitarse la autorización para trabajar por no tratarse de ofertas de empleo con dificultades para ser gestionadas. Nada más lejos de la realidad. Más detalles en https://www.sepe.es/HomeSepe/empresas/informacion-paraempresas/profesiones-de-dificil-cobertura/profesiones-mas-demandadas.html
} 
se han mercantilizado, continúan siendo "cosas de mujeres" tanto por quién las realiza como por quién las contrata y gestiona su trabajo. El trabajo reproductivo sigue atribuyéndose a las mujeres, sin cuestionar las relaciones patriarcales en la sociedad que apenas cambian en el ámbito privado ante la falta de compromiso e implicación de los varones en él. De poco sirve que la ley garantice la igualdad formal si, diseñadas las políticas públicas en términos de igualdad, su implementación práctica demuestra, con datos empíricos, que las usuarias/beneficiaras de las mismas siguen siendo las mujeres casi en exclusividad dado que los varones se sienten al margen de todo lo relacionado con los cuidados y el hogar familiar. Este sector es un observatorio privilegiado que evidencia la vigencia de la división sexual del trabajo clásica que descansa sobre la explotación laboral de las sustitutas o servidoras y perpetúa la discriminación en un mercado laboral profundamente segmentado. Y es evidente que, frente a ello, es necesario tanto fomentar de la corresponsabilidad intrafamiliar porque la infravaloración del trabajo femenino conduce a su desprofesionalización como incentivar la formación y cualificación del colectivo y los servicios que presta, fundamentales, ineludibles en el nuevo contexto social que la incorporación de las mujeres al mercado de trabajo dibuja en el presente y, como no, en el futuro inmediato.

Como ya se ha indicado en alguna ocasión anterior, hay quienes encuentran las razones en nuestra historia reciente ${ }^{14}$. Y es que, para los historiadores del Derecho "a través del análisis histórico-jurídico de la normativa social de los diversos periodos de la Dictadura franquista, observamos como el servicio doméstico es el gran marginado de todas las ampliaciones de derechos sociales que lentamente se practicaron ${ }^{15}$ ". A mayor abundamiento, "el franquismo negó a la mujer su desarrollo personal y profesional postergándola al hogar (...). De este modo, vemos como la empleada del hogar es una suerte de "miembro putativo" de la familia, una extensión de la misma, motivo por el cual el Estado debe ceder ante la potestad del cabeza de familia (...). Podemos afirmar que el servicio doméstico durante el franquismo concentró sobre la mujer la marginación, la represión y la discriminación de cuarenta largos años de Dictadura ${ }^{16 "}$. Y es que cuesta, temporalmente hablando, superar concepciones tan arraigadas en nuestro ADN como ésta. Es obvio que superar 40 años ya no de retraso, sino de regresión política y social, por mucho que estemos demostrando ganas de superar y dejar atrás, lleva su proceso. Pero llama poderosamente la atención que países de nuestro entorno constitucional hayan culminado positivamente ese mismo proceso y, sin embargo, España lo haya iniciado pero muy tímidamente.

\footnotetext{
${ }^{14}$ Vid. más detalles en GRAU PINEDA, Carmen, "De sirvientas a trabajadoras: la necesaria ratificación del Convenio 189 OIT sobre trabajo decente para las trabajadoras y los trabajadores domésticos", Revista Jurídica de los Derechos Sociales Lex Social, 2019, vol. 9, n 2, pp. 72 y ss.

${ }^{15}$ CAÑABATE PEREZ, José, ““'Servir es distinto a trabajar”: Potestad del cabeza de familia vs. Protección social del servicio doméstico en la dictadura franquista”, en GARCIA GONZALEZ, Guillermo, BONET ESTEVA, Margarita Y ESPUGNY I TOMAS, M. a . Jesús (coord.), Relaciones laborales y empleados del hogar: reflexiones jurídicas, Dykinson, 2014, p. 61.

${ }^{16}$ CAÑABATE PEREZ, José, “"Servir es distinto a trabajar”: Potestad del cabeza de familia vs. Protección social del servicio doméstico en la dictadura franquista”, op. cit., p. 80.
} 
Pero también soy de las que opinan que hay otra razón principal: la etnización de este sector. Tercer factor de discriminación que, junto a la feminización y la segregación ocupacional, consolidan la vulnerabilidad característica de las trabajadoras de este sector $^{17}$. Los datos son sesudos y demuestran que en aquellos países en los que la brecha entre ricos y pobres es considerable, la demanda de mano de obra suele satisfacerse internamente, a menudo recurriendo a migrantes nacionales procedentes de zonas rurales. A escala mundial, sin embargo, las trabajadoras domésticos son, muy a menudo, migrantes internacionales. Si bien hace cuarenta años la migración para trabajar en el servicio doméstico era un fenómeno aislado, hoy se cree que las trabajadoras domésticas representan un porcentaje importante de la mano de obra migrante en todo el mundo. La demanda de trabajadoras domésticas ${ }^{18}$ es uno de los factores clave que explican la feminización de la migración, tanto Sur-Norte como Norte-Norte o en otras rutas migratorias mundiales ${ }^{19}$.

La contratación de las mujeres inmigrantes posibilita, en España y en los países desarrollados, la conciliación de la vida laboral y familiar de las mujeres nativas que, sin apoyos públicos, resuelven sus dificultades laborales recurriendo, de forma privada, a las primeras y provocando con ello un "trasvase de desigualdades de mujeres", dando lugar a la construcción de mujeres "servidas" y mujeres "servidoras" 20 . Para muchas mujeres inmigrantes, trabajar en el servicio doméstico se convierte en la única opción laboral que tienen al llegar y esto está estrechamente relacionado no solo con la normativa laboral sino, además, con la de inmigración y extranjería. Y es que, "la capacidad para contratar al amparo de este tipo de relaciones especiales a quienes no ostentan la nacionalidad española se halla condicionada (...) por la compleja normativa sobre extranjería. (...) Es preciso tener en cuenta que se trata de un sector de la economía en el que la presencia de trabajadores extranjeros es absolutamente mayoritaria, por no decir casi exclusiva. (...) Esta posición "subalterna" se ha visto reforzada por el hecho de que el trabajo doméstico se ha convertido en una de las principales vías de incorporación de la mujer extranjera al mercado de trabajo ${ }^{21}$ ". En suma, lo que se ha dado en denominar la "cadena transnacional del cuidado", es la que "ha garantizado durante años la pervivencia del capitalismo patriarcal a la vez que ha invisibilizado su naturaleza excluyente. La crisis de los cuidados no ha sido resuelta, de esta manera, mediante una generalizada y equitativa implicación

\footnotetext{
${ }^{17}$ Más detalles sobre la discriminación múltiple característica de este colectivo en SANZ SÁEZ, Concha, "La discriminación en contra de las empleadas de hogar como forma de manifestación de las discriminaciones múltiples", Revista de Derecho Social, 2018, nº 83, pp. 89-108.

${ }^{18}$ Aunque se constata un número marginal de hombres trabaja en el sector - con frecuencia como jardineros, chóferes, mayordomos o porteros -, sigue siendo un sector donde son mayoría las mujeres.

${ }^{19}$ OELZ, Martin, "El Convenio y la Recomendación de la OIT sobre las trabajadoras y los trabajadores domésticos. Una oportunidad para la justicia social”, Revista Internacional del Trabajo, vol. 133, n 1, 2014, p. 163.

${ }^{20}$ PARELLA RUBIO, Sonia, "El trasvase de desigualdades de clase y etnia entre mujeres: los servicios de proximidad", Papers, 2000, no 60, pp. 275-289.

${ }^{21}$ GRAU PINEDA, Carmen y DOMÍNGUEZ-MUJICA, Josefina, "La persistencia de mujeres inmigradas en el servicio doméstico en España en tiempos de recesión económica: datos para la reflexión", Revista de derecho migratorio y extranjería, 2015, $\mathrm{n}^{\circ}$ 40, p. 84.
} 
de los hombres en el trabajo del cuidado, ni un fortalecimiento de las responsabilidades reproductivas del estado ni, por descontado, una feministización del mercado laboral ${ }^{22}$ ".

Todo ello permite concluir que se está en presencia de un sector emergente, un yacimiento de empleo, un servicio esencial a la comunidad y una actividad cuya demanda seguirá una tendencia creciente ante la falta de provisión pública de cuidados y que, por el bien de todos, es preciso replantear de forma inminente en la siguiente línea: dignificarla y profesionalizarla. Y para ello el papel de la formación y la cualificación profesional es innegable se mire por donde se mire.

\section{2. ¿Existe un derecho laboral a la formación profesional para este colectivo?}

Con carácter previo se ha querido dejar clara una premisa que se considera de partida, basilar: el derecho a la formación de todas las personas trabajadoras y la importancia que la formación tiene en todos los sectores productivos y respecto de todas las ocupaciones y perfiles abarca también el empleo doméstico y conviene no olvidarlo y tenerlo muy presente.

El derecho a la formación como derecho laboral básico viene recogido tanto en los arts. $27^{23}, 35.1^{24}$ y $40.2^{25} \mathrm{CE}$ como en el art. 4.2. $\mathrm{b}^{26} \mathrm{ET}$ que garantizan, en general, tanto la educación y la formación profesional como la promoción a través del trabajo. En este ámbito que nos ocupa, el RD 1620/2011 que regula la relación laboral de carácter especial del servicio del hogar familiar (derogando su precedente inmediato, el RD 1424/1985), reconoce a las personas trabajadoras de este sector todos los derechos y deberes establecidos en los arts. 4-5 de la norma estatutaria. Por tanto, resulta meridiamente claro que el art 4.2.b) ET antedicho es de plena aplicación al empleo doméstico, sin especialidad o matización alguna.

Como acertadamente se ha señalado, "el derecho y el deber del trabajador de formarse profesionalmente debe asumirse como elemento esencial de la propia actividad laboral,

\footnotetext{
${ }^{22}$ EZQUERRA, Sandra, "Crisis de los cuidados y crisis sistémica: la reproducción como pilar de la economía llamada real", Revista Investigaciones Feministas, 2011, vol. 2, p. 190

${ }^{23}$ Todos tienen el derecho a la educación. Se reconoce la libertad de enseñanza. 2. La educación tendrá por objeto el pleno desarrollo de la personalidad humana en el respeto a los principios democráticos de convivencia y a los derechos y libertades fundamentales.

${ }^{24}$ Todos los españoles tienen el deber de trabajar y el derecho al trabajo, a la libre elección de profesión u oficio, a la promoción a través del trabajo y a una remuneración suficiente para satisfacer sus necesidades y las de su familia, sin que en ningún caso pueda hacerse discriminación por razón de sexo.

${ }^{25}$ 1. Los poderes públicos promoverán las condiciones favorables para el progreso social y económico y para una distribución de la renta regional y personal más equitativa, en el marco de una política de estabilidad económica. De manera especial realizarán una política orientada al pleno empleo.

2. Asimismo, los poderes públicos fomentarán una política que garantice la formación y readaptación profesionales; velarán por la seguridad e higiene en el trabajo y garantizarán el descanso necesario, mediante la limitación de la jornada laboral, las vacaciones periódicas retribuidas y la promoción de centros adecuados.

${ }^{26}$ Art. 4.2 ET. En la relación de trabajo, los trabajadores tienen derecho: b) A la promoción y formación profesional en el trabajo, incluida la dirigida a su adaptación a las modificaciones operadas en el puesto de trabajo, así como al desarrollo de planes y acciones formativas tendentes a favorecer su mayor empleabilidad.
} 
con la influencia que ello debe tener sobre el régimen jurídico que posteriormente la regulación ordinaria decida otorgar a una u otra concepción de la actividad formativa. No obstante, el acto de formarse es actualmente para el trabajador un derecho y deber que, como ciudadano, le acompaña más que nunca en el marco de la relación laboral. En fin, las circunstancias que en el presente presiden las relaciones laborales españolas, caracterizadas por su elevada tasa de temporalidad y por su tendencia hacia la flexibilidad en todas sus variantes, invitan a robustecer la formación continua del trabajador dependiente y reconocer explícitamente en el marco constitucional la relevancia que ha adquirido la misma ${ }^{27}$ ".

Y si se hace el ejercicio de extrapolar todo ello al ámbito que nos ocupa, resulta que para que los servicios tanto domésticos como de cuidados intrafamiliares en el domicilio sean eficaces, las trabajadoras del sector también deben mejorar tanto sus competencias genéricas como la garantía de calidad de los servicios prestados en este sector. El papel de la formación en este ámbito ha de ser capaz de identificar, partiendo de la gama de competencias que necesitan las personas trabajadoras, los programas de formación más adecuados y hacer las recomendaciones necesarias para mejorar la formación en el campo.

En el modelo que España ha adoptado, la cualificación profesional puede ser adquirida a través de diferentes itinerarios. En concreto, se reconocen tres vías para obtener cualificaciones profesionales:

a) La vía formal, superando los módulos formativos de los certificados de profesionalidad o de cualquier enseñanza regulada por el sistema educativo "con significación para el empleo";

b) La vía de la experiencia laboral, a través del reconocimiento y la acreditación de la experiencia práctica de la actividad laboral, que puede implicar la exención total o parcial del módulo de Formación en el centro de trabajo, y;

c) Las vías no formales de adquisición de competencias, mediante el aprendizaje acumulado "a lo largo y ancho de la vida", como por ejemplo cursillos, seminarios, prácticas no laborales en empresas, etc.

Lo que promueve el marco normativo español de formación profesional, que se expondrá a continuación, es la clasificación de las cualificaciones profesionales "con arreglo a un catálogo que, organizado por módulos y ajustado a los requerimientos del sistema productivo, facilite la evaluación y acreditación de competencias profesionales, admitiendo que pueda alcanzarse el mismo resultado por otras vías menos estructuradas o formales (...). A partir de tal organización de la formación profesional se pretende promover el seguimiento y conjugación de las ofertas formativas de formación profesional, facilitándose su consecución mediante una articulación modular que permite

${ }^{27}$ REQUENA MONTES, Óscar, Formación profesional continua y prestación de trabajo: El artículo 23 del Estatuto de los Trabajadores como mecanismo de conciliación, Tesis doctoral, 2019, disponible en acceso abierto en TESEO, p. 151. 
la "acreditación parcial acumulable" de las cualificaciones adquiridas a través de cualquier vía ${ }^{28 ",}$.

En definitiva, los instrumentos de acreditación y certificación oficial -con validez en todo el territorio nacional- de las cualificaciones y competencias profesionales contenidas en el Catálogo Nacional de Cualificaciones Profesionales (CNCP) descansan sobre el siguiente tándem: por un lado, los títulos de formación profesional, que acreditan las enseñanzas de la formación profesional de ciclo largo o reglada, y, por otro lado, los certificados de profesionalidad, procedentes de la formación profesional de ciclo corto, entre la que destaca la formación profesional para el empleo, sin perjuicio de que puedan obtenerse estos certificados por otras vías. Pero veámoslo detenidamente.

\section{Las tres W: What, why and who?: ¿De qué formación se trata?, ¿por qué no se le da importancia a la formación de las personas trabajadoras en este sector?, ¿quién no lo hace?}

\section{1. ¿De qué formación se dispone?. Una radiografía de la oferta formativa existente.}

En el empleo doméstico, es frecuente que muchas personas trabajadoras pese a tener una dilatada experiencia profesional, no dispongan de la acreditación oficial necesaria para optar a determinados puestos de trabajo. Obvio es que cuando una persona dispone de estas competencias profesionales y es capaz de realizar correctamente las tareas propias de su puesto de trabajo, esté cualificada para ejercer su profesión, si bien, es frecuente, como decimos, que no suela contar con un documento oficial que lo reconozca y acredite como tal. Precisamente por ello, y como se verá a continuación, el establecimiento tanto de ciclos formativos de formación profesional inicial como de certificados de profesionalidad como documentos oficiales que acreditan la capacidad para ejercer esta actividad profesional viene a permitir (o ese es su leitmotiv) acceder en mejores condiciones a las ofertas de empleo del sector.

Como acertadamente se ha señalado, "la práctica que se adquiere mediante la formación profesional, modifica, moldea y enriquece la profesionalidad del trabajador, elemento de reveladora importancia en la relación de trabajo, puesto que resulta inseparable al carácter personalísimo de esta relación. A diferencia de la situación "tradicional", ahora se quiere cada vez más, "un profesional". En realidad, lo que esto parece indicar, es que la tendencia actual va en la dirección de seleccionar personas más productivas ${ }^{29}$ ". Pero en el empleo doméstico y a falta de la concreción de su contenido - ¿qué son tareas domésticas y de cuidados?- esto no ocurre, principalmente, como se ha tenido ocasión de adelantar, por su invisibilidad e infravaloración.

Cuesta comprender que siendo un lugar común pensar que disponer de competencias acordes con la demanda requerida de los puestos de trabajo continúa siendo la clave de bóveda en el éxito laboral, esto no sea así en el empleo doméstico, máxime la vertiginosa

\footnotetext{
${ }^{28}$ Ídem, pp. 174-175.

29 SANZ SÁEZ, Concha, "Profesionalización efectiva del servicio doméstico. Un trabajo pendiente", Revista jurídica de los Derechos Social Lex Social, 2019, vol. 9, nº 2, p. 308.
} 
transformación que está teniendo en las últimas décadas como consecuencia de los cambios sociales anticipados. En los momentos que se viven, resulta paradójico que lo que cuenta cuando se contrata de una persona trabajadora de cualquier sector productivo, parece no contar para una trabajadora doméstica respecto de la que se pretende otorgue satisfacción inmediata a nuestras necesidades familiares sin preocuparnos por su formación/cualificación profesional en ese sentido y confiando en que cuenta con tales competencias por el simple hecho biológico de ser mujer. Por mucho que las actividades específicas a realizar -sean las que fueren a falta de concreción u objetivación- puedan realizarse de modo genérico, es evidente que se requiere de una básica formación/cualificación profesional para ello. Como en todas las ocupaciones, trabajos y actividades, cuanto mayor sea la técnica adquirida, mayor será la competencia y profesionalidad alcanzada en la prestación del servicio. Increíble tener que recordar esto. Y ello solo puede deberse a lo ya antedicho: la creencia de que el simple hecho biológico de ser mujer capacita de forma automática para la prestación de ciertas tareas como es el caso de las domésticas y de cuidados intrafamiliares.

Todo ello ha provocado que ante sectores (éste y otros) que presentan dificultades concretas de acreditación de competencias profesionales, se haya decidido regular títulos de formación profesional inicial (básicos) y certificados de formación profesional para el empleo (certificados de profesionalidad). Es importante tener en cuenta que tanto la formación profesional inicial como la formación profesional para el empleo son subsistemas de la Formación Profesional que, si bien dependen de ministerios distintos (Ministerio de Educación y de Empleo, respectivamente), están compuestas por cualificaciones profesionales modulares que permiten la convalidación entre ambos subsistemas ${ }^{30}$.

\subsubsection{La Formación Profesional Inicial específica: el ciclo formativo de formación profesional básica en actividades domésticas y limpieza de edificios}

El Catálogo Nacional de Cualificaciones Profesionales (CNCP), al que se ha hecho mención líneas atrás, es el instrumento del Sistema Nacional de las Cualificaciones y

\footnotetext{
${ }^{30}$ La cualificación profesional describe un conjunto de competencias profesionales con significación en el empleo que pueden ser adquiridas mediante formación modular u otros tipos de formación, así como a través de la experiencia laboral (ex Ley Orgánica 5/2002, de 19 de junio, de las Cualificaciones y de la Formación Profesional). Este conjunto de competencias profesionales (conocimientos y capacidades) permite dar respuesta a ocupaciones y puestos de trabajo relevantes, con valor y reconocimiento en el mercado laboral. Se concreta en un documento que recoge de forma estructurada dichas competencias y una vez aprobado, se publica en el BOE en forma de Real Decreto. En ningún caso regula la profesión o actividad profesional, lo que corresponderá a las diferentes Administraciones competentes según el sector o ámbito de desarrollo. La cualificación no se corresponde con un plan de formación, sino que es la referencia, en el sistema integrado de formación profesional que describe la Ley Orgánica 5/2002, de 19 de junio, para que se elaboren los certificados de profesionalidad y los títulos de formación profesional. Cada cualificación se identifica mediante un código único que incluye la familia profesional a la que se asocia y su nivel [1, 2 o 3]. La competencia general define brevemente los cometidos y funciones esenciales del profesional. El entorno profesional describe el ámbito profesional en el que se desarrolla la actividad especificando el tipo de organizaciones, áreas o servicios; los sectores productivos, las ocupaciones y puestos de trabajo relacionados.
} 
Formación Profesional (SNCFP) que ordena las cualificaciones profesionales susceptibles de reconocimiento y acreditación, identificadas en el sistema productivo en función de las competencias apropiadas para el ejercicio profesional. Comprende las cualificaciones profesionales más significativas del sistema productivo español, organizadas en familias profesionales y niveles. Constituye la base y el referente para elaborar la oferta formativa de los títulos de formación profesional y los certificados de profesionalidad. El CNCP incluye el contenido de la formación profesional asociada a cada cualificación, de acuerdo con una estructura de módulos formativos articulados. Y es el Instituto Nacional de las Cualificaciones (INCUAL) el responsable de definir, elaborar y mantener actualizado el CNCP y el correspondiente Catálogo Modular de Formación Profesional.

Dicho esto, siendo la Ley Orgánica 5/2002, de 19 de junio, de las Cualificaciones y de la Formación Profesional el referente normativo de partida, como normativa de desarrollo en la materia es de destacar el Real Decreto 1128/2003, de 5 de septiembre, por ser el encargado de regular dicho catálogo, si bien ha sido después modificado en varias ocasiones: el Real Decreto 1416/2005, de 25 de noviembre, incorporó modificaciones puntuales; el Real Decreto 817/2014, de 26 de septiembre, vino a incorporar aspectos puntuales de las cualificaciones profesionales para cuya modificación, procedimiento de aprobación y efectos es de aplicación el artículo 7.3 de la Ley Orgánica 5/2002 antedicha; y varios Reales Decretos son los encargados de aprobar las diferentes cualificaciones profesionales. En suma, un sistema normativo prolijo y complejo en el que, en lo que a nuestro interés va referido, destaca el Real Decreto 1179/2008, de 11 de julio, por el que se complementa el CNCP, mediante el establecimiento de diecisiete cualificaciones profesionales de nivel 1, correspondientes a determinadas familias profesionales (anexo CDXIII), entre las que se encuentra la familia profesional de servicios socioculturales dentro de la que se ubica el trabajo doméstico y de cuidados. Este último, ha sido, a su vez, modificado por obra del Real Decreto 721/2011, de 20 de mayo, se establecen cuatro certificados de profesionalidad de la familia profesional servicios socioculturales y a la comunidad que se incluyen en el repertorio nacional de certificados de profesionalidad y se actualizan otros, entre ellos el de empleo doméstico ${ }^{31}$.

La actualización de los currículos formativos de la formación profesional básica ${ }^{32}$ (en el ámbito de gestión del Ministerio de Educación) ha sido una constante para ir adaptándolos

\footnotetext{
${ }^{31}$ Artículo 2. Certificados de profesionalidad que se establecen.

Los certificados de profesionalidad que se establecen corresponden a la familia profesional Servicios socioculturales y a la comunidad y son los que a continuación se relacionan, cuyas especificaciones se describen en los anexos que se indican respecto de la Familia profesional: Servicios Socioculturales y a la Comunidad:

Anexo I. Empleo doméstico. Nivel 1.

Anexo II. Dinamización comunitaria. Nivel 3.

Anexo III. Inserción laboral de personas con discapacidad. Nivel 3.

Anexo IV. Mediación comunitaria. Nivel 3

${ }^{32}$ Teniendo en cuenta el cambios introducido en la FP a través de la LOMCE (LO 8/2013, 9 de octubre, para la mejora de la calidad educativa), el RD 1147/2011 es el encargado de adaptarse a la nueva ordenación en esta área dando paso a la FP Básica tal y como hoy la conocemos.
} 
a las necesidades que de ellos se demandan, pero también la actualización de los certificados de profesionalidad de la formación profesional para el empleo. Las modificaciones/adaptaciones de ambos subsistemas han ido a la par, como no podía ser de otro modo, si bien las diferencias entre ambos son ostensibles en virtud de sus distintas filosofías formativas.

En cuanto a los primeros, esto es, los ciclos formativos de la formación profesional básica, el RD 774/2015, de 28 de agosto, estableció seis títulos entre los que se incluyó “Título profesional básico en actividades domésticas y limpieza de edificios" y cuyo currículo sería desarrollado por la Orden ECD/648/2016 que lo configura de la siguiente forma:

Ciclo formativo de formación profesional básica en actividades domésticas y limpieza de edificios

\begin{tabular}{|c|c|c|c|c|}
\hline \multirow{2}{*}{ Módulos } & \multirow{2}{*}{$\begin{array}{c}\text { Duración } \\
\text { (horas) }\end{array}$} & \multirow{2}{*}{$\begin{array}{l}\text { Primer } \\
\text { curso } \\
\text { (h/s) }\end{array}$} & \multicolumn{2}{|c|}{ Segundo curso } \\
\hline & & & $(\mathrm{h} / \mathrm{s})$ & Horas \\
\hline 3098. Mantenimiento de prendas de vestir y ropa de hogar. & 275 & 7 & & \\
\hline 3102. Cocina doméstica. & 275 & 7 & & \\
\hline $\begin{array}{l}\text { 3145. Actividades de apoyo a personas no dependientes en } \\
\text { la unidad convivencial. }\end{array}$ & 130 & 4 & & \\
\hline 3009. Ciencias aplicadas I. & 160 & 5 & & \\
\hline 3011. Comunicación y sociedad I. & 160 & 5 & & \\
\hline Tutoría. & & 2 & & \\
\hline $\begin{array}{l}\text { 3104. Limpieza de domicilios particulares, edificios, oficinas } \\
\text { y locales. }\end{array}$ & 200 & & 8 & \\
\hline 3116. Limpieza con máquinas. & 80 & & 3 & \\
\hline 3146. Seguridad en el ámbito doméstico. & 130 & & 4 & \\
\hline 3042. Ciencias aplicadas II. & 160 & & 6 & \\
\hline 3012. Comunicación y sociedad II. & 190 & & 7 & \\
\hline Tutoría. & & & 2 & \\
\hline
\end{tabular}

\begin{tabular}{r|r|r|r|r}
\hline 3147. Formación en centros de trabajo. & 240 & & & 240 \\
\hline Total en el ciclo formativo ................. & 2000 & 30 & 30 & 240 \\
\hline
\end{tabular}

Cuadro 1. Orden ECD/648/2016, de 26 de abril, por la que se establece el currículo de seis ciclos formativos de formación profesional básica en el ámbito de gestión del Ministerio de Educación, Cultura y Deporte en BOE de 3 de mayo, pp. 29750-29751.

Se trata, por tanto, de un ciclo formativo de formación profesional básica o inicial que se presenta con una duración extensa (2.000 horas repartidas en dos cursos académicos) y con un vasto contenido (desde mantenimiento de ropa, cocina doméstica o cuidado de no dependientes pasando por ciencias aplicadas, comunicación y sociedad, seguridad en el ámbito doméstico o limpieza de máquinas). Un título que hace una oferta, en mi opinión, interesante y completa que poco tiene que ver con los módulos formativos dentro de la formación profesional para el empleo que se centran en los contenidos más básicos de esta relación laboral pero que, obviamente, van dirigidos a colectivos distintos y con objetivos claramente diferentes: en general, el primero a jóvenes que optan por la formación profesional básica en lugar de la educación secundaria obligatoria; mientras el segundo a jóvenes y no tan jóvenes que, ante la falta de otras alternativas pueden 
decantarse por esta suerte de formación profesional para el empleo/acreditación de la experiencia laboral, como se verá a continuación.

Para acceder al ciclo formativo de formación profesional básica en actividades domésticas y limpieza de edificios es preciso cumplir con los tres requisitos siguientes:

- Tener cumplidos quince años, o cumplirlos durante el año natural en curso, y no superar los diecisiete años de edad en el momento del acceso o durante el año natural en curso.

- Haber cursado el primer ciclo de Educación Secundaria Obligatoria o, excepcionalmente, haber cursado el segundo curso de la Educación Secundaria Obligatoria.

- Haber propuesto el equipo docente a los padres, madres o tutores legales la incorporación del estudiante a un ciclo de Formación Profesional Básica.

Y entre los variados y diversos contenidos de aprendizaje se encuentran desde limpiar, higienizar y desinfectar aseos, cocinas y estancias en domicilios particulares y edificios, organizar las actividades domésticas relacionadas con la alimentación en domicilios particulares o lavar, planchar, ordenar y coser la ropa del hogar y las prendas de vestir; pasando por otras como resolver problemas predecibles relacionados con su entorno físico, social personal y productivo, actuar de forma saludable en distintos contenidos cotidianos que favorecen el desarrollo personal y social o valorar las actuaciones encaminadas a la conservación del medio ambiente; y terminando por algunas referidas a cumplir las normas de calidad, las medidas de prevención de riesgos laborales ejercer sus derechos y cumplir sus obligaciones derivadas de su actividad profesional.

Superado el ciclo formativo de formación profesional básica referido se podrá obtener el certificado de profesionalidad en actividades domésticas y limpieza de edificios y que capacita para trabajar como:

- Limpiador doméstico / limpiadora doméstica.

- Cocinero doméstico / cocinera doméstica.

- Planchador doméstico / planchadora doméstica.

- Empleada / empleado de hogar.

- Limpiador / limpiadora.

- Peón especialista de limpieza.

- Especialista de limpieza.

- Limpiador / limpiadora de cristales.

El objetivo, por tanto, no es otro que formar profesionales que puedan ejercer su actividad por cuenta ajena tanto en domicilios particulares como en empresas públicas o privadas de cualquier tamaño. Además, podrán desarrollar su actividad profesional en el sector de la limpieza e higienización de toda clase de edificios, locales, centros o instituciones sanitarias y de salud, públicos o privados, industrias, elementos de transporte (terrestre, aéreo, marítimo), máquinas, espacios e instalaciones, soportes publicitarios y mobiliario 
urbano. Así como desempeñar sus funciones siguiendo instrucciones recibidas y bajo la supervisión directa de un responsable, pudiendo trabajar de forma autónoma o integrarse en un equipo de trabajo.

Y, además, permite el acceso, si fuera el caso, a título de formación profesional de grado medio, con preferencia en la admisión a todos los títulos de grado medio de las familias profesionales de Textil, Confección y Piel, Hostelería y Turismo y Servicios Socioculturales y a la Comunidad. Concretamente, una extensión formativa de continuidad bien pudiera ser la de Técnico en Atención a Personas en situación de dependencia destinado a capacitar a profesionales que ejerzan su actividad en el sector de servicios a las personas: asistenciales, psicosociales y de apoyo a la gestión doméstica y que certifica poder trabajar como:

- Cuidador / cuidadora de personas en situación de dependencia en diferentes instituciones y / o domicilios.

- Gobernante / gobernanta y subgobernante / subgobernanta de personas en situación de dependencia en instituciones.

- Auxiliar responsable de planta de residencias de mayores y personas con discapacidad.

- Auxiliar de ayuda a domicilio.

- Asistente de atención domiciliaria.

- Trabajador / trabajadora familiar.

- Auxiliar de educación especial.

- Asistente personal.

- Teleoperador / teleoperadora de teleasistencia.

Sea como fuere, quiere adelantarse el escaso éxito de esta oferta formativa. Hoy por hoy solo se oferta en 18 centros, frente a los casi 450 que ofertan algunos de los ciclos de grado medio antedichos. Centros educativos y localidades que en la mayoría de las ocasiones nos sugieren zonas deprimidas, clase social baja y altas tasas de fracaso escolar, desempleo juvenil y de larga duración, con lo que resulta que la formación impartida también parece tener un cierto sesgo de clase social. 


\begin{tabular}{|c|c|c|c|c|c|}
\hline Provincia & Localidad & Denominación Genérica & Denominación Específica & Código & Naturaleza \\
\hline Las Palmas & Gran Tarajal & Instituto de Educación Secundaria & VIGÁN & 35010610 & $\begin{array}{l}\text { Centro } \\
\text { público }\end{array}$ \\
\hline Las Palmas & $\begin{array}{l}\text { Las Palmas de } \\
\text { Gran Canaria }\end{array}$ & Instituto de Educación Secundaria & SCHAMANN & 35010208 & $\begin{array}{l}\text { Centro } \\
\text { público }\end{array}$ \\
\hline Las Palmas & $\begin{array}{l}\text { Las Palmas de } \\
\text { Gran Canaria }\end{array}$ & Instituto de Educación Secundaria & TONY GALLARDO & 35009899 & $\begin{array}{l}\text { Centro } \\
\text { público }\end{array}$ \\
\hline Las Palmas & Valle de Jinámar & Instituto de Educación Secundaria & LILA & 35010142 & $\begin{array}{l}\text { Centro } \\
\text { público }\end{array}$ \\
\hline Albacete & Albacete & Centro de Educación Especial & ELOY CAMINO & 02003569 & $\begin{array}{l}\text { Centro } \\
\text { público }\end{array}$ \\
\hline Albacete & Hellin & Centro de Educación Especial & CRUZ DE MAYO & 02003739 & $\begin{array}{l}\text { Centro } \\
\text { público }\end{array}$ \\
\hline Toledo & Toledo & Centro de Educación Especial & CIUDAD DE TOLEDO & 45005574 & $\begin{array}{l}\text { Centro } \\
\text { público }\end{array}$ \\
\hline Badajoz & Badajoz & Centro Privado de Educación Especial & $\begin{array}{l}\text { CENTRO DE FORMACIÓN PROFESIONAL } \\
\text { ESPECIAL EXTREMA DORII }\end{array}$ & 06012516 & $\begin{array}{l}\text { Centro } \\
\text { privado }\end{array}$ \\
\hline Badajoz & Valdelacalzada & Instituto de Educación Secundaria & IES MARIA JOSEFA DE BARAINCA & 06007791 & $\begin{array}{l}\text { Centro } \\
\text { público }\end{array}$ \\
\hline Cáceres & Moraleja & Instituto de Educación Secundaria & JALAMA & 10007525 & $\begin{array}{l}\text { Centro } \\
\text { público }\end{array}$ \\
\hline Pontevedra & Covaterreña & Instituto de Educación Secundaria (IES) & Primeiro de Marzo & 36019657 & $\begin{array}{l}\text { Centro } \\
\text { público }\end{array}$ \\
\hline Pontevedra & Pontevedra & $\begin{array}{l}\text { Centro Integrado de Formación } \\
\text { Profesional }\end{array}$ & A Xunqueira & 36014489 & $\begin{array}{l}\text { Centro } \\
\text { público }\end{array}$ \\
\hline Alicante/Alacant & Alicante/Alacant & Instituto de Educación Secundaria & GRAN VÍA & 03014861 & $\begin{array}{l}\text { Centro } \\
\text { público }\end{array}$ \\
\hline Araba/Álava & Vitoria-Gasteiz & $\begin{array}{l}\text { Centro Privado de Educación Infantil } \\
\text { Primaria y Secundaria }\end{array}$ & PAULA MONTAL & 01001188 & $\begin{array}{l}\text { Centro } \\
\text { privado }\end{array}$ \\
\hline Araba/Álava & Vitoria-Gasteiz & $\begin{array}{l}\text { Centro Privado de Formación } \\
\text { Profesional }\end{array}$ & BERMAR & 01007671 & $\begin{array}{l}\text { Centro } \\
\text { privado }\end{array}$ \\
\hline Bizkaia & Bilbao & $\begin{array}{l}\text { Centro Privado de Educación Infantil } \\
\text { Primaria y Secundaria }\end{array}$ & ANGELES CUSTODIOS & 48002328 & $\begin{array}{l}\text { Centro } \\
\text { privado }\end{array}$ \\
\hline Bizkaia & Bilbao & $\begin{array}{l}\text { Centro Privado de Educación } \\
\text { Secundaria }\end{array}$ & MARIA INMACULADA & 48003311 & $\begin{array}{l}\text { Centro } \\
\text { privado }\end{array}$ \\
\hline Bizkaia & Santurtzi & & CALASANZ LANBIDE IKASTEGIA & 48007405 & $\begin{array}{l}\text { Centro } \\
\text { privado }\end{array}$ \\
\hline Gipuzkoa & $\begin{array}{l}\text { Donostia/San } \\
\text { Sebastián }\end{array}$ & $\begin{array}{l}\text { Centro Privado de Educación } \\
\text { Secundaria }\end{array}$ & MARIA INMACULADA & 20004848 & $\begin{array}{l}\text { Centro } \\
\text { privado }\end{array}$ \\
\hline Gipuzkoa & Zumarraga & & UROLA GARAIKO LANBIDE ESKOLA & 20005956 & $\begin{array}{l}\text { Centro } \\
\text { privado }\end{array}$ \\
\hline
\end{tabular}

Cuadro

2.

https://www.educacion.gob.es/centros/buscar.do?shortcut=1\&codaut=00\&codprov=00\&ssel_natur=0\&co $\underline{\text { mboniv}=141 \& \text { combofam }=120123 \& \text { textofamilia=SERVICIOS } \% 20 \text { SOCIOCULTURALES } \% 20 Y \% 20 \mathrm{~A} \%}$ 20LA\%20COMUNIDAD\%20(LOE)\&comboens=12312301\&textoensenanza=Actividades\%20Dom\%e9s ticas\%20y\%20Limpieza\%20de\%20Edificios

\subsubsection{La Formación Profesional para el empleo específica: el certificado de profesional para el empleo doméstico}

La formación para el empleo es considerada un instrumento clave para reforzar la productividad y competitividad de las empresas españolas así como para acreditar la empleabilidad de las personas trabajadoras ${ }^{33}$.

El desarrollo del derecho a la promoción y formación profesional en el trabajo reconocido en los arts. 4.2.b) y $23 \mathrm{ET}^{34}$ necesita ser concretado y, para ello, se remite prioritariamente

\footnotetext{
${ }^{33}$ In extenso en NIETO ROJAS, Patricia, "El nuevo Sistema de Formación Profesional para el empleo (Ley 30/2015 y RD 694/2017) y el papel de los agentes sociales en su desarrollo", Revista de Información Laboral, $2018, \mathrm{n}^{\circ} 7$.

34 Dentro de este subsistema de formación profesional, interesa diferenciar que hay una formación profesional obligatoria (ex lege y en supuestos como los relacionados con la prevención de riesgos laborales o las necesidades concretas de la empresa como la adaptación) y otra voluntaria a la que se dedica en exclusiva el art. 23 ET encargado de la formación programada dentro de la empresa.
} 
a la negociación colectiva y, subsidiariamente, al acuerdo individual. Y, en este sentido, se ha señalado cómo "es, precisamente, en este ámbito (negociación colectiva) donde debiese producirse un ajuste más preciso e inmediato de la oferta y la demanda de competencias profesionales a partir de una detección adecuada de las necesidades formativas de las plantillas, de la planificación de la formación, y de la utilización y gestión de los recursos disponibles en el sistema ${ }^{35 "}$. Dicho lo cual, en este sector en el que ni existe convenio colectivo ni se lo espera por lo que se dirá más delante, todo ello no hace sino poner en evidencia la gravedad de las dificultades formativas. Hay quienes se aventuran a hablar de "brecha de representación" 36 " en este sector en el que la escasa sindicación y la nula negociación colectiva en un país con elevada cobertura convencional están dificultando alcanzar los estándares de empleo decente que las instituciones mundiales han establecido como básicos y esenciales ${ }^{37}$.

El sistema de Formación Profesional para el empleo ha venido a desarrollarse por obra, primero, de la Ley 30/2015 y, después, del Real Decreto 694/2017. La referida Ley 30/2015 acomete una reforma integral del sistema de formación profesional para el empleo (en la línea predeterminada tanto por la Ley de Empleo 26/2003 como por el acuerdo sobre la Formación Profesional para el empleo de 2014 y el RDL 3/2011 en un intento por mejorar la empleabilidad de la clase trabajadora y conseguir que la Formación Profesional para el empleo (en adelante, FP) contribuya a superar los déficits formativos siempre denunciados y nunca removidos con éxito. Esta reforma integral se estructura en cuatro objetivos estratégicos: 1. La garantía del ejercicio del derecho a la formación de trabajadores, empleados y desempleados, en particular, de los más vulnerables; 2. La contribución efectiva de la formación a la competitividad de las empresas: 3. El fortalecimiento de la negociación colectiva en la adecuación de la oferta formativa a los requerimientos del sistema productivo, así como la eficiencia y transparencia en la gestión de los recursos públicos; y 4. Consolidar en el sistema productivo una cultura de formación profesional y favorecer con ello la creación de empleo estable y de calidad.

En desarrollo de la anterior norma legal, es, primero, el RD 34/2008 (18 de enero) el encargado de regular, en general, los certificados de profesionalidad y, después, el RD 1179/2008 (11 de julio) por el que se complementa el CNCP, mediante el establecimiento de diecisiete cualificaciones profesionales de nivel 1, correspondientes a determinadas familias profesionales, entre ellas la de servicios socioculturales en que se encuadra el empleo doméstico, el encargado de formular un sistema modular de 240 horas de duración - que es el que mejor se adecua a los intereses personales y laborales de los interesadas y

\footnotetext{
35 NIETO ROJAS, Patricia, "El nuevo Sistema de Formación Profesional para el empleo (Ley 30/2015 y RD 694/2017) y el papel de los agentes sociales en su desarrollo", op. cit., n 7, p. 4 de la versión electrónica. ${ }^{36}$ GÓMEZ ABELLEIRA, Francisco Javier en "El trabajo al servicio del hogar: algunas propuestas desde el proyecto europeo PHS-QUALITY", $10.07 .2020 . \quad$ Disponible en https://forodelabos.blogspot.com/2020/07/el-trabajo-al-servicio-del-hogar.html

37 SALCEDO BELTRÁN, Carmen, "El trabajo doméstico en España: planteamientos y desafíos insoslayables frente a la "esclavitud moderna", Revista General de Derecho del Trabajo y de Seguridad Social, Iustel, 2020, $\mathrm{n}^{\circ}$ 55, p. 2.
} 
permite diseñar su itinerario formativo tanto de forma presencial como a distancia en función de sus concretas necesidades- que incluye tres módulos formativos sobre acondicionamiento de camas y ropa, limpieza y cocina doméstica que, básicamente, capacitan o cualifican para dedicarse profesionalmente a la ocupación de limpiador/a, cocinero/a y planchador/a domésticos/as y, en definitiva, empleado/a de hogar (que aglutina todas las anteriores).

Por tanto, España, como otros países de nuestro entorno comparado más cercano como es el caso de Francia ${ }^{38}$, ha considerado oportuno implementar un modelo que se sustenta sobre la base de la obtención de un título formativo básico/certificado de profesionalidad, según los casos, que aglutina los conocimientos, competencias $^{39}$ y cualificaciones ${ }^{40}$ profesionales necesarias para realizar correctamente las tareas propias de esta actividad laboral. Por todos es sabido la importancia de las certificaciones oficiales en la era de la meritocracia que se vive y, precisamente por ello, se trata de un documento oficial otorgado por los servicios públicos de empleo autonómicos o estatal y que tiene validez en todo el territorio nacional.

En este segundo supuesto, el certificado de profesionalidad para el empleo doméstico comprende las acciones formativas dirigidas a la adquisición y mejora de las competencias y cualificaciones profesionales, tiene carácter modular con el fin de favorecer la acreditación parcial acumulable de la formación recibida y posibilitar al trabajador que avance en su itinerario de formación profesional para el empleo cualquiera que sea su situación laboral en cada momento y acredita una cualificación profesional del CNCP.

\footnotetext{
${ }^{38}$ El país galo cuenta con 3 certificados profesionales, compuestos por 4 bloques comunes y 4 bloques específicos, certificables, todos ellos, separadamente y accesibles a través de la formación o de la validación de la experiencia profesional (casi 600 horas); más de 70 módulos de formación continua (entre 14 y 40 horas de duración) y un acompañamiento específico para la validación de la experiencia profesional que incluyen las tareas y los cuidados familiares (empleo doméstico, asistente de niños y asistente de dependientes). Más detalles en https://www.francecompetences.fr/

${ }^{39}$ Es el conjunto de conocimientos, capacidades, habilidades y otros comportamientos que permiten ejercer de forma adecuada las tareas que se tienen que realizar en una determinada profesión. Las competencias indican la forma de comportarse o actuar en determinadas situaciones y están formadas por los conocimientos, las aptitudes y las actitudes y las capacidades.

${ }^{40}$ Es un conjunto de competencias profesionales importantes para el empleo que pueden ser adquiridas mediante formación, o a través de la experiencia laboral. Acreditar las competencias profesionales contribuye al desarrollo personal y profesional, ya que permite: Obtener un documento oficial válido en todo el territorio español, que permite demostrar a una persona sus competencias profesionales; valorar la experiencia profesional; contar con más posibilidades para acceder a un empleo; y completar y mejorar la formación para aumentar las competencias profesionales.
} 


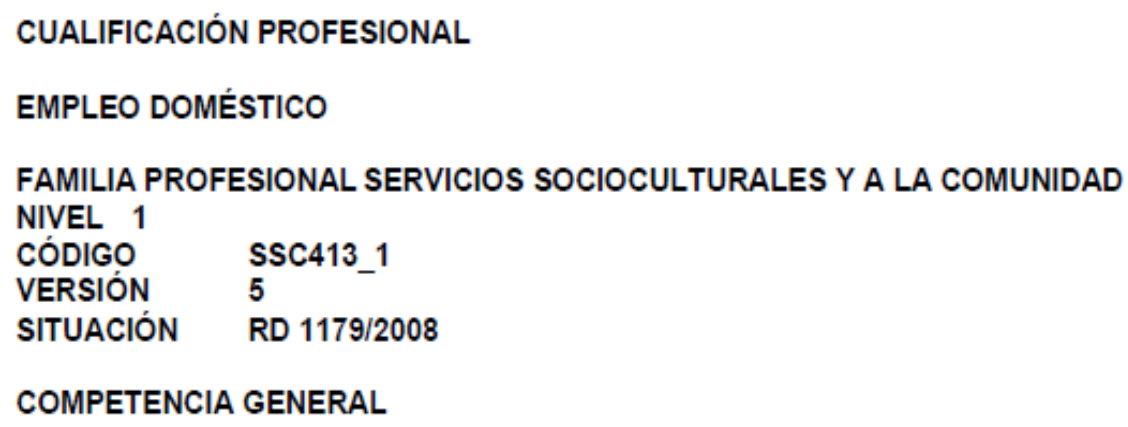

Realizar las tareas de limpieza de superficies y mobiliario de la vivienda, de elaboración de alimentos, de lavado y planchado, cosido básico manual y preparado de camas, seleccionando y empleando las técnicas, útiles, productos y electrodomésticos para garantizar la higienización del domicilio y permitir la disponibilidad de uso de las camas, la ropa de hogar, las prendas de vestir y el consumo de alimentos, cumpliendo con la normativa de prevención de riesgos laborales.

\section{UNIDADES DE COMPETENCIA}

UC1332 1: Efectuar el proceso de lavado, planchado y cosido básico manual de prendas de vestir y ropa de hogar, y la preparación de camas, en domicilio particular.

UC1330_1: Realizar la limpieza de domicilios particulares, en domicilio particular.

UC1331_1: Realizar el proceso de elaboración de alimentos en sus fases de compra, organización, manipulāción, cocinado y conservación, en domicilio particular.

\section{ENTORNO PROFESIONAL}

\section{Ámbito Profesional}

Desarrolla su actividad profesional tanto por cuenta propia como ajena en el ámbito público y privado. Así mismo, la persona profesional está capacitada para realizar la limpieza y preparación de domicilios particulares.

\section{Sectores Productivos}

Se ubica en el sector doméstico en las siguientes actividades productivas: limpieza y mantenimiento del domicilio, lavado, planchado, cosido básico manual de prendas de vestir y ropa de hogar, preparación de camas y compra y elaboración básica de alimentos.

Ocupaciones y puestos de trabajo relevantes

- Limpiador/a doméstico/a. Cocinero/a doméstico/a Planchador/a doméstico/a Empleado/a de hogar.

\section{FORMACIÓN ASOCIADA (240 HORAS)}

Módulos Formativos

MF1332_1: Acondicionamiento de camas, prendas de vestir y ropa de hogar.(90 h)

MF1330_1: Limpieza doméstica.(60 h)

MF1331_1: Cocina doméstica. $(90 \mathrm{~h})$

Cuadro 3. Real Decreto 721/2011, de 20 de mayo, por el que se establecen cuatro certificados de profesionalidad de la familia profesional Servicios socioculturales y a la comunidad que se incluyen en el Repertorio Nacional de certificados de profesionalidad y se actualizan los certificados de profesionalidad establecidos como anexo I y II en el Real Decreto 1379/2008, de 1 de agosto, en BOE de 23 de junio, pp. 66305-66306.

Solo repárese en que nada hay de cuidados, como sí se prevé en el ciclo formativo de la formación profesional inicial antedicho aunque sea a nivel muy básico, dado que esa formación tiene prevista impartirse en otro certificado de profesionalidad, este de nivel 2 sobre atención sociosanitaria de personas en el domicilio (RD 295/2004) cuyos contenidos pueden verse en el siguiente cuadro, pero que no hacen sino evidenciar como se mantiene el empeño por separar tareas y cuidados intrafamiliares (excluyendo la atención especializada a las personas dependientes) como si ello fuera posible en la 
mayoría de los casos y reclamando con urgencia la objetivación del contenido que le es propio al empleo doméstico. Mientras no se acometa esa labor de determinación material, será difícil que la formativa no solo acierte sino sea apetecible e interesante a las personas trabajadoras del sector que quieran formarse por atender a las necesidades que se les requieren. Este segundo certificado, el de atención sociosanitaria a personas en el domicilio, es más conocido y popular que el primero -el de empleo doméstico, prácticamente desconocido y difícil de conseguir-, se requiere para trabajar en empresas que ofrecen este servicio bajo cobertura púbica o institucional y que, precisamente por ello, es considerado socialmente como "un verdadero trabajo", "una verdadera profesión".

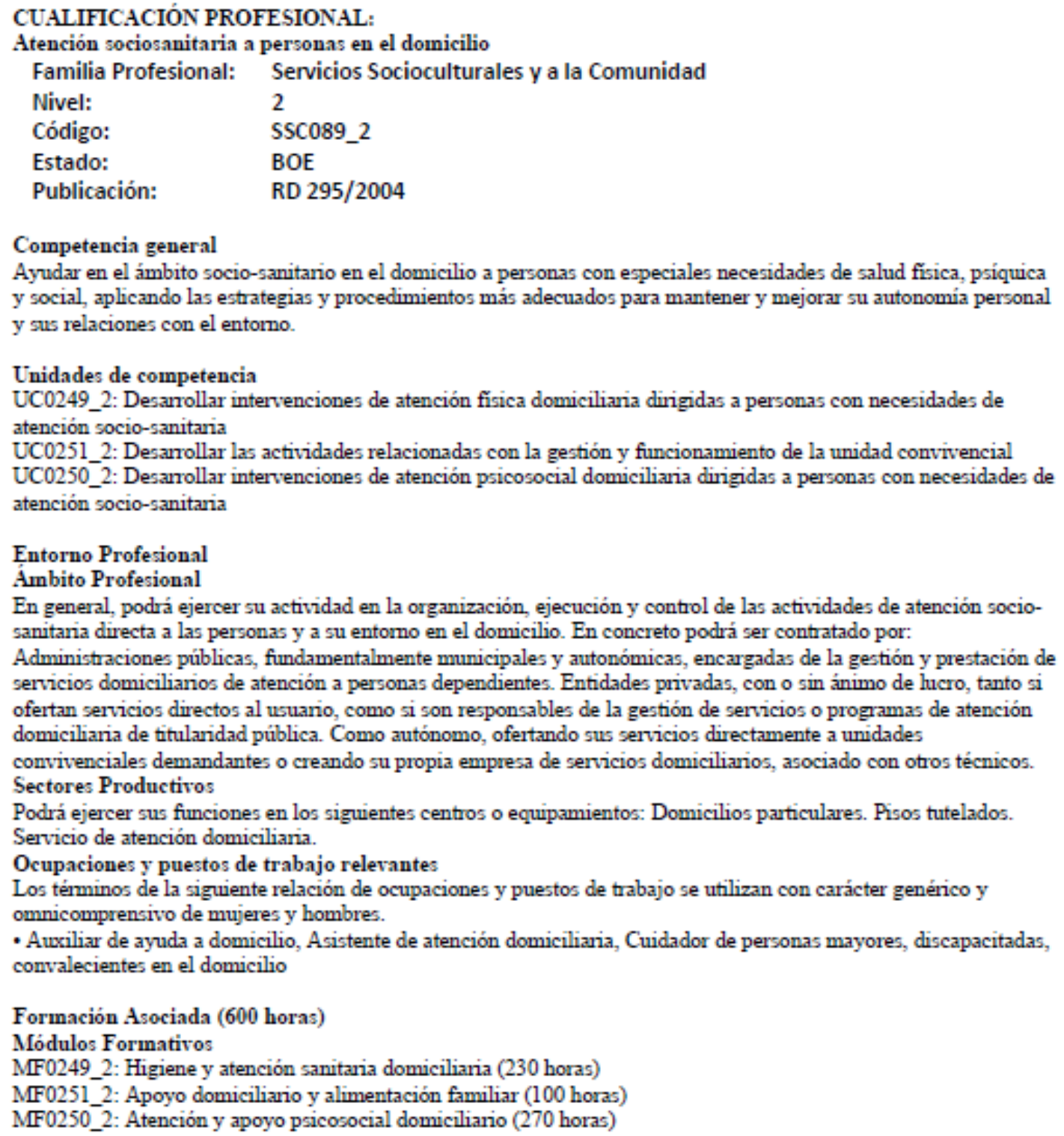

Cuadro 4. Real Decreto 295/2004, de 20 de febrero, por el que se establecen determinadas cualificaciones profesionales que se incluyen en el Catálogo nacional de cualificaciones profesionales, así como sus correspondientes módulos formativos que se incorporan al Catálogo modular de formación profesional, en BOE de 09 de marzo, Anexo LXXXIX. 
Al margen del supuesto concreto de acceso al ciclo formativo antedicho de la formación profesional básica, lo más habitual en la praxis, es que las personas trabajadoras en este sector se decanten (por razón de la edad, las dificultades de compatibilidad trabajo/estudios, etc.) bien por alcanzar este certificado profesional vía la realización de cursos de FP para el empleo ofertados por los servicios públicos de empleo estatal o autonómicos; bien por acceder al mismo vía la acreditación de la experiencia laboral o la formación no reglada que se tenga y, para ello, es preciso iniciar un procedimiento de reconocimiento, evaluación y acreditación de las competencias profesionales ${ }^{41}$. En estos casos, y dado que no haremos ninguna referencia posterior, quiere apuntarse que podrá obtenerse el certificado de profesionalidad vía el procedimiento de reconocimiento, evaluación y acreditación de las competencias profesionales que es convocado por las administraciones públicas competentes en función de las necesidades del mercado laboral y consiste en realizar las comprobaciones necesarias para determinar si una persona tiene las competencias necesarias para ejercer una determinada profesión. Para ello, se le pide a la persona que demuestre lo que sabe hacer, cómo realiza las tareas propias de un puesto de trabajo. Una vez superadas estas comprobaciones se puede obtener una acreditación oficial con validez en todo el territorio nacional.

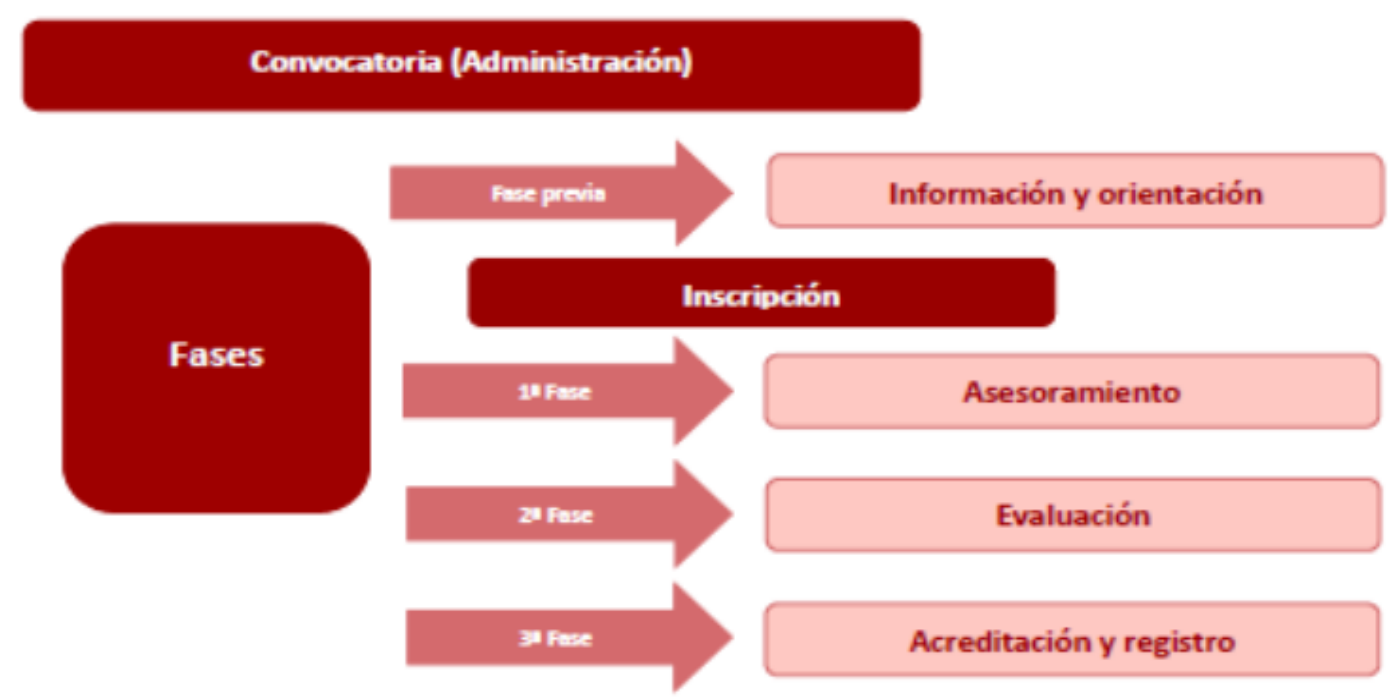

Cuadro 5: UGT-PV, Cualificaciones profesionales del empleo doméstico, Valencia, UGT-PV, 2016, p. 10 .

\footnotetext{
${ }^{41}$ En este supuesto, hay tres tipos de requisitos (ex RD 1224/2009, de 17 de julio): edad, experiencia laboral y formación: tener 18 años cumplidos al realizar la inscripción si es para unidades de competencia de una cualificación profesional de nivel I o 20 años cumplidos al realizar la inscripción si es para unidades de competencia de cualificaciones profesionales de nivel II y III; contar con experiencia laboral adquirida en los últimos 10 años relacionada con las competencias que el candidato quiera acreditar de 2 años (1200 horas mínimas trabajadas) para cualificaciones de nivel I o de 3 años (2000 horas mínimas trabajadas) para cualificaciones de nivel II y III; y, por último, tener formación, realizada en los últimos 10 años también, relacionada con las competencias que el candidato quiera acreditar y, concretamente, 200 horas para cualificaciones de nivel I o 300 horas para cualificaciones de nivel II y III.
} 
Dicho esto, solo consta que se hayan hecho dos convocatorias entre los años 2018-2019 en la Comunidad Foral de Navarra, frente a las frecuentes convocatorias formuladas en todo el territorio nacional respecto de otras especialidades de la misma familia profesional (atención sociosanitaria a personas en el domicilio o atención sociosanitaria a personas dependientes en instituciones sociales) ${ }^{42}$. Lo que da mucho que pensar en la línea señalada tanto de falta de visibilización como de profesionalización de este sector.

\section{2. ¿Por qué no se demuestra eficaz este sistema y quién es el responsable de ello?: la importancia fundamental del asociacionismo y sindicación de las trabajadoras del sector}

Llegados a este punto y siendo una obviedad reconocer la mejora de las condiciones de trabajo de este sector que han contribuido a visibilizarlo, también es innegable que los problemas que persisten en materia de representación y negociación de este colectivo tienen por consecuencia que se haya conseguido mucho menos de lo deseado.

En otros sectores poco organizados como éste, el papel desempeñado por la ley ha sido fundamental tanto para reducir la desigual capacidad de negociación de trabajadores y empleados como para proteger a las personas trabajadoras. En España, siendo innegable las positivas consecuencias derivadas de las reformas de 2011, los datos acumulados desde 2015 demuestran que, si en un primer momento aumentaron las afiliaciones, con posterioridad descendió el número de ocupadas, sin haber sido posible alcanzar las optimistas cifras de "afloramiento" previstas en aquellos momentos, sobre todo, por el incremento de los costes que la afiliación supone para los empleadores (las familias). Que ha habido aumento cuantitativo en el sector, lo avalan las cifras más recientes; pero no ha sido la esperada, ni mucho menos, máxime conociendo las cifras de trabajo informal existentes y que rondan el 70\% (EFSI, 2018: 22), informalidad que no es sino el síntoma de las limitaciones que existen respecto del marco legal vigente.

Siendo cierto y verdad que la aprobación de estas normas supuso en España un paso considerable en el afianzamiento de los derechos laborales de las personas trabajadoras de este sector, es fundamental tanto reducir las trabas administrativas que supone para familias y empleadas la oficialización de sus relaciones laborales como incentivar económicamente la suscripción de estas. Por tanto, remoción de trabas administrativas y acciones de estímulo económico público como ejes fundamentales del tránsito de la informalidad a la formalidad del sector. Pero, además, es crucial mantener su presencia en la agenda política para evitar posibles estancamientos y enfrentar los desafíos que aún quedan pendientes como la ratificación del Convenio 189 OIT. Y para ello resulta perentorio, además, dotarlas de mayor protección colectiva. Afortunadamente, desde hace un tiempo se vienen formando asociaciones de trabajadoras domésticas a fin de canalizar sus demandas y denuncias, y los sindicatos también les han dado cobertura, integrándolos en su estructura y promoviendo acciones para su promoción y apoyo. Es más, se dice que la no ratificación del Convenio 189 OIT está en el origen del movimiento asociativo

\footnotetext{
${ }^{42}$ https://sede.sepe.gob.es/recex/RXBuscadorConvocatoriaWebRED/busquedaConvocatorias.do
} 
reivindicativo. En otras palabras, la no ratificación del Convenio 189 OIT, asignatura pendiente para España y flagrante incumplimiento de sus compromisos internacionales, está funcionando, de facto, como el elemento actual de unidad fundamental del movimiento de defensa de los derechos de las trabajadoras domésticas que han centrado sus reivindicaciones en la necesidad de incorporar la protección por desempleo, pero también en la necesidad de fomentar, desde las instituciones públicas, el asociacionismo y sindicación de las trabajadoras domésticas o de promover organizaciones de empleadores e intermediarios con los que poder negociar sus condiciones laborales ${ }^{43}$.

\subsubsection{Problemas de representación sindical y/o empresarial}

A nivel europeo, sólo en unos cuantos países, como Francia e Italia, existen federaciones de empleadores de trabajadores domésticos que permiten llevar a cabo negociaciones colectivas.

a) En Italia tres sindicatos negociaron un primer acuerdo colectivo con la Federación Nacional del Clero Italiano y dos asociaciones patronales/de empleadores en 1974. Durante las siguientes cuatro décadas los empleadores se organizaron para establecer sus propias organizaciones de representación: la Associazione Nazionale Famiglie Datori di Lavoro Domestico (DOMINA) y la Federazione Italiana Datori di Lavoro Domestico (FIDALDO). La FIDALDO firmó el correspondiente acuerdo en 1996 y la DOMINA lo hizo en 2001. El acuerdo vigente en la actualidad fue firmado en 2013 e incluye tasas de salarios, períodos de descanso, vacaciones pagadas, subsidio de enfermedad e indemnización por despido. El acuerdo carece de aplicación universal, ya que obliga únicamente a los empleadores miembros de la DOMINA o la FIDALDO, o a aquellos que firmaron contratos que remitieran explícita o implícitamente a los acuerdos de negociación. Cuando los trabajadores no cubiertos formalmente por estos contratos acuden a los tribunales, las disposiciones sobre salarios y seguridad social son las normas en que se basan los jueces para dictar sentencia. A pesar de las limitaciones mencionadas, en el sector del trabajo doméstico la situación ha mejorado significativamente en los últimos quince años y ha aumentado considerablemente el número de trabajadores que ha firmado contratos tipo.

b) En Francia, las relaciones triangulares han dado lugar a una serie de acuerdos colectivos con diferentes organizaciones de empleadores, que actuaban en representación de los cabeza de familia empleadores o de intermediarios y organismos (públicos o privados). El primero de estos acuerdos fue firmado en 1999 por las siguientes confederaciones sindicales: Fédération des particuliers employeurs de France (FEPEM), Confédération française démocratique du travail (CFDT), Confédération Générale du Travail (CGT), Confédération française des travailleurs chrétiens (CFTC) y Force Ouvrière (FO), y beneficiaba únicamente a trabajadores remunerados por particulares y empleados por los diferentes hogares. Se firmaron dos acuerdos más: uno en 2012, que

\footnotetext{
${ }^{43}$ GRAU PINEDA, Carmen, "De sirvientas a trabajadoras: la necesaria ratificación del Convenio 189 OIT sobre trabajo decente para las trabajadoras y los trabajadores domésticos", op. cit., pp. 82 y ss.
} 
firmaron seis sindicatos y dos organizaciones de empleadores, y beneficiaba a trabajadores domésticos colocados en viviendas de particulares por intermediarios sin fines lucrativos; y el segundo, firmado en 2014 por tres sindicatos y dos organizaciones de empleadores en representación de empresas privadas, que beneficiaba a trabajadores domésticos empleados por empresas privadas. Considerados conjuntamente, estos acuerdos abarcan la mayor parte del sector del trabajo doméstico que está cuantificado en 3.4 millones de empleadores particulares y 1.4 millones de trabajadores que generan 8.7 millones de euros en salarios pagados y 1.6 millones de horas declaradas ${ }^{44}$.

No cabe la menor duda que tanto la descentralización como el aislamiento en el que prestan sus servicios de las trabajadoras domésticas y el hecho de que, normalmente, no tengan compañeros y compañeras de trabajo, constituyen serias dificultades al ejercicio de sus derechos colectivos de asociación, representación y negociación colectiva. Cierto es que el ordenamiento jurídico español no lo prohíbe, pero sí que las "dificultades para su ejercicio, no han sido resueltas por la norma reglamentaria con una adaptación a las condiciones de los trabajadores de este sector ${ }^{45}$ ". Y precisamente por ello es necesario aumentar la implicación política en este sentido de cara a lograr un mayor peso colectivo que les dé más fuerza, alentando derechos cruciales como el de la negociación colectiva con una incidencia directa en otros como el de formación. Y es que, por seguir en el modelo francés, dentro del sector existen 2 ramos profesionales con sendos acuerdos colectivos, fruto de un diálogo social muy positivo para ambas partes: trabajadores de empleadores particulares que regula tres perfiles profesionales -empleados domésticos, asistentes de dependientes y de niños ${ }^{46}$ - y asistentes infantiles de empleadores particulares con un único perfil profesional, esto es, el de asistentes infantiles que cuidan niños en sus domicilios y no en el de los niños, previa autorización de la administración competente y sujeta a un máximo de niños, un mínimo de espacio, medidas de seguridad, etc. ${ }^{47}$.

Se considera que, sin desmerecer otro tipo de organizaciones, son los sindicatos "los sujetos colectivos que deberían asumir prioritariamente esta importante función, por ser estructuras ya existentes, por la relevancia que se les reconoce, por las funciones que están llamados a desarrollar y por tener capacidad de unificar las reivindicaciones de los

\footnotetext{
${ }^{44}$ FEPEM, Le secteur des particuliers employeurs et de l'emploi à domicile. Rapport sectoriel des branches, 2020, pp. 6-7, disponible en https://www.fepem.fr/wp-content/uploads/Rapport-sectoriel-desBranches 2020 VF.pdf

${ }^{45}$ SANZ SÁEZ, Concha, "Derechos colectivos y empleadas del hogar: reformas jurídicas inaplazables para un trabajo decente del trabajo doméstico en España", comunicación presentada y seleccionada respecto de la conversación II "Trabajo decente para todos" en el Congreso Interuniversitario OIT sobre el futuro del trabajo, Sevilla, 2019, 7-8 febrero, p. 19.

${ }^{46}$ Convention collective nationale des salariés du particulier employeur du 24 novembre 1999, disponible enhttps://www.legifrance.gouv.fr/conv_coll/id/KALITEXT000005672603?tab_selection=all\&searchField =ALL\&query=Convention+collective+nationale+des+salaries+du+particulier+employeur\&page $=1$ \&init $=$ $\underline{\text { true }}$

${ }^{47}$ Convention collective nationale des assistants maternels du particulier employeur du 1er juillet 2004. Etendue par arrêté du 17 décembre 2004 JORF 28 décembre 2004, disponible en https://www.legifrance.gouv.fr/conv_coll/id/KALICONT000005635807/
} 
trabajadores del sector, y por tanto, de actuar con mayor fuerza colectiva ${ }^{48}$ ". Pero, donde no los haya, también cabe que se organicen a través de cooperativas o asociaciones. Y en nuestro país, ambas posibilidades ( sindicación $^{49}$ y asociacionismo ${ }^{50}$ )) son factibles con los mimbres actuales y el marco jurídico establecido que equipara (por lo menos a nivel laboral) este colectivo al resto de trabajadores por cuenta ajena ${ }^{51}$. Y es que para que la negociación colectiva sea un hecho, las leyes y políticas deben contemplar la posibilidad de proceder a negociaciones colectivas sectoriales en las que queden representados las trabajadoras domésticas y las organizaciones de sus empleadores ${ }^{52}$. Cuando ha habido voluntad política para solucionar problemas operativos como los apuntados, se han encontrado soluciones. Según algunos ejemplos aportados por la OIT $^{53}$, las organizaciones de amas de casa preexistentes se han reconocido cada vez más como empleadoras a la hora de negociar en países como Alemania y Uruguay. En Alemania, por ejemplo, el sindicato $N G G$ fue el que pidió a la $D H B$ que actuase en calidad de asociación representante del empleador. Y, en Uruguay, después de que la Cámara de Comercio rehusara una invitación para actuar como contraparte empleadora, se pidió a la Liga de Amas de Casa, Consumidores y Usuarios de la República Oriental del Uruguay (LACCU) que participara en un Consejo de Salarios de Trabajadores Domésticos, Grupo 21, junto con el Ministerio de Trabajo y Seguro Social y el SUTD. En definitiva, "querer es poder", pero nadie dijo que fuera fácil conseguirlo y el reto sindical por hacer suyas las reivindicaciones del colectivo y atraerlo hacia las estructuras sindicales organizadas es importante.

\subsubsection{Problemas derivados de la prioridad de otros aspectos diferentes a los formativos que se consideran preferentes: prevención de riesgos laborales y protección por desempleo}

En la actualidad, es innegable la existencia en nuestro país una relativa preocupación sindical por este colectivo si bien la formación no está entre los aspectos fundamentales que marcan la acción sindical. De forma absolutamente lógica, entre las reivindicaciones

\footnotetext{
${ }^{48}$ MIÑARRO YANINI, Margarita, "Formas esclavas de trabajo y servicio del hogar familiar: delimitación conceptual, problemática específica y propuestas", Relaciones Laborales, n 10, 2014, p. 87.

${ }^{49}$ Pese a tratarse de un movimiento incipientes son ya dos los sindicatos específicos Sindicato de Trabajadoras del Hogar y los Cuidados (SINTRAHOCU, 2020) y SINDIHOGAR (2011), lo que pone de manifiesto las sinergias e inquietudes existentes a respecto.

${ }^{50}$ También hay algunos referentes de ámbitos más limitados pero que están en la génesis del movimiento sindical antedicho: asociación de trabajadoras/es del hogar de Sevilla, asociación de trabajadoras del hogar de Bilbao (ATH-ELE), asociación Servicio doméstico activo (SEDOAC, 2005) que cuenta con un centro de atención integral y una red de apoyo al colectivo d dimensión nacional, entre otras.

${ }^{51}$ Téngase en cuenta que el Convenio OIT n ${ }^{\circ} 163$ sobre negociación colectiva (1981) garantiza que las partes en la negociación colectiva deberían estar en condiciones de elegir los niveles más apropiados de negociación colectiva y, en caso de ser necesario, se deberían adoptar las medidas adecuadas a las condiciones nacionales para que ésta pueda desarrollarse en cualquier nivel y especialmente, a nivel "del establecimiento, de la empresa, de la rama de actividad, de la industria y a nivel regional o nacional (art. 4.1)

${ }^{52}$ OIT, Voz y representación de los trabajadores domésticos a través de la organización, Nota informativa 8 , OIT.

${ }^{8}$ Ídem.
} 
sindicales enmarcables en este sector se encuentra la ratificación del convenio $\mathrm{n}^{\circ} 189$ OIT, la urgente integración de este colectivo en el ámbito subjetivo de aplicación de la Ley de prevención de riesgos laborales (LPRL) y equiparación definitiva en materia tanto laboral como de seguridad social con la ampliación de la protección social hacia el desempleo como se ha puesto de manifiesto durante la pandemia del COVID-19.

Y es que, como se ha señalado, "en el plano de las resistencias, más costosas de superar por lo que suponen de oposición o protesta frente al cambio que suponen, es posible encontrar dos principales: la referida a la exclusión del trabajo doméstico de la aplicación de la Ley de Prevención de Riesgos Laborales y de la protección por desempleo. Sendas exclusiones representan una merma de considerable repercusión en el marco protector del trabajo doméstico y se encuentran en el epicentro de todos los problemas de ratificación ${ }^{54}$ ".

Respecto de lo primero, se conculca el mandato de la OIT según el cual "todo trabajador doméstico tiene derecho a un entorno de trabajo seguro y saludable. Todo Miembro, en conformidad con la legislación y la práctica nacionales, deberá adoptar medidas eficaces, teniendo debidamente en cuenta las características especificadas del trabajo doméstico, a fin de asegurar la seguridad y salud en el trabajo de los trabajadores domésticos" (ex art. 13 Convenio 189). España ha optado por dejar fuera del ámbito objetivo de aplicación de la LPRL al trabajo doméstico y justifica esta exclusión tanto en la especial interrelación que en este trabajo existe entre trabajador y empleador como en las peculiaridades del lugar donde se presta. Justificación que no parece suficiente ya que existen otras figuras tales como el trabajo a distancia -recientemente regulado por el RDL 28/2020- que no han sido excluidos. Y, sin embargo, los riesgos laborales aumentan por el hecho de que "los hogares son ambientes que no están designados ni regulados en un principio para constituir lugares de trabajo y por ello, a diferencia de la industria, no están sujetos a una evaluación de riesgos o a los requisitos necesarios para obtener licencias ${ }^{55}$ ". Probablemente, "la solución más viable hubiese sido (...) que el legislador hubiera optado por aplicar la normativa contenida en la LPRL salvo en determinadas cuestiones en las que se recurriría a una normativa reglamentaria específica para solventar aquellos aspectos que no fueran compatibles con las peculiaridades de la relación laboral especial. A este respecto, se apuntan otras posibles soluciones, tales como las que arbitra cierto sector doctrinal referidas a la posibilidad de mantener este tipo de relación al margen del ámbito de aplicación de la LPRL y haber previsto una futura regulación reglamentaria ${ }^{56}$ ". A nadie escapa el hecho de que el trabajo doméstico entrañe riesgos específicos que requieren del correspondiente desarrollo reglamentario y la propia OIT en el informe de

\footnotetext{
${ }^{54}$ GRAU PINEDA, Carmen, "De sirvientas a trabajadoras: la necesaria ratificación del Convenio 189 OIT sobre trabajo decente para las trabajadoras y los trabajadores domésticos", op. cit., pp. 79 y ss.

${ }^{55}$ OIT, La inspección del trabajo y otros mecanismos de cumplimiento en el sector del trabajo doméstico: Guía introductoria, op. cit., p. 11.

56 SANZ SÁEZ, Concha, "La discriminación en contra de las empleadas de hogar como forma de manifestación de las discriminaciones múltiples", Revista Derecho Social, no 83, 2018, pp. 99-104.
} 
la Comisión de Expertos en aplicación de las normas internaciones del trabajo $2019^{57}$, con ocasión de las observaciones de la UGT sobre exclusión de las trabajadoras domésticas de la LPRL, recuerda al Estado español que las personas trabajadoras domésticas, muchas de ellas migrantes, son particularmente vulnerables a abusos y explotación.

Respecto de la segunda de las exclusiones referidas, se deja fuera de la protección por desempleo a este sector -bajo sospechas de algún tipo de fraude encubierto en la relación de confianza que lo caracteriza- conculcando el mandato de la OIT de "asegurar que los trabajadores domésticos disfruten de condiciones no menos favorables que las condiciones aplicables a los trabajadores en general con respecto a la protección de la seguridad social" (ex art. 14 Convenio 189). La ya referida DA 2 ${ }^{\text {a }}$ RD 1620/2011 preveía, además, que la acción protectora del Sistema Especial para Empleados de Hogar (SEEH) "no comprenderá la correspondiente al desempleo. Eso se entiende sin perjuicio de las iniciativas que puedan establecerse con respecto a esta cuestión en el marco de la renovación de la relación laboral de carácter especial del servicio del hogar familiar". Dentro del mandato dirigido al grupo de expertos antes adelantado, se preveía que se informase también respecto de la creación de un mecanismo de protección por desempleo para este colectivo "adaptado a las peculiaridades de la actividad del servicio del hogar familiar que garantice los principios de contributividad, solidaridad y sostenibilidad financiera". La ausencia de la protección por desempleo -ya contenida en el Régimen Especial de Empleados de Hogar (REEH), antes de ser integrado en el $\mathrm{RGSS}^{58}$ - choca ahora, sin embargo, con la progresiva extensión de la protección por desempleo a colectivos de trabajadores por cuenta ajena que han estado o están aún hoy insertos en regímenes especiales y que antes carecían de esta previsión ${ }^{59}$. Esta falta de cobertura implica un grave perjuicio para las empleadas de hogar que, por el momento, permanece tal cual sin que parezca próxima su inclusión (DA 39a .3. f. Ley 27/2011 $\left.{ }^{60}\right)^{61}$. Pues bien, las eventuales modificaciones que deberían haberse producido en todos los sentidos referidos e implementado antes de finales del año 2013, según el propio RD

\footnotetext{
57 OIT: Aplicación de las normas internacionales del trabajo, 2019, Informe de la Comisión de Expertos en Aplicación de Convenios y Recomendaciones, Informe III (Parte A), OIT, 2019, p. 643.

${ }^{58}$ Y que encontraba su soporte jurídico en el artículo 3.2 de la Ley 31/1984, de 2 de agosto, de protección por desempleo, según el cual aquélla alcanza a todos los trabajadores por cuenta ajena, haciendo depender dicha inclusión del hecho de estar contemplada esta contingencia en los regímenes especiales.

${ }^{59}$ Más detalles en SANZ SÁEZ, Concha, La protección social de las empleadas de hogar. La desaparición del Régimen Especial de la seguridad Social y su integración en el Régimen General como Sistema Espacial: análisis actual y de futuro, Bomarzo, 2017.

${ }^{60}$ Ley 27/2011, de 1 de agosto, sobre actualización, adecuación y modernización del sistema de Seguridad Social cuya DA 39a.3. f prevé que "la acción protectora del Sistema especial para Empleados de Hogar no comprenderá la correspondiente al desempleo. Eso se entiende sin perjuicio de las iniciativas que puedan establecerse con respecto a esta cuestión en el marco de la renovación de la relación laboral de carácter especial del servicio del hogar familiar".

${ }^{61}$ Otra de las promesas incumplidas es la equiparación en materia de cotización por salarios reales y en materia de cobertura respecto de sectores que continúa siendo una realidad inmaterial máxime "gracias" a la enmienda 6777 presentada por el grupo parlamentario popular al proyecto de PGE 2019 y acatada por el PSOE y que retrasa de forma irreversible el proyecto de equiparación hasta el 2024.
} 
27/2011 y como paso previo a la ratificación del Convenio 189 OIT no se han materializado por el momento. De hecho, ni el referido grupo de expertos llegó a constituirse, ni consta que esté previsto hacerlo a medio plazo $^{62}$, pese a los problemas sociales gravísimos detectados como consecuencia de la crisis sanitaria del COVID-19 en este sentido y que han requerido de la aprobación de un subsistido al que pocas trabajadoras domésticas han podido acceder como consecuencia de la elevada informalidad idiosincrásica del sector.

Dicho lo cual, y como se desprende de lo anterior, no está tan presente como debiera entre las preocupaciones sindicales la formación como elemento de dignificación, de valoración decisiva en este sector productivo y respecto del colectivo concreto que estamos tratando. Se considera un hecho de menor importancia frente a otras preocupaciones sindicales de mayor calado que por ir referidas a las idiosincrásicas condiciones de trabajo tienen un mayor protagonismo o repercusión. La formación en España, históricamente ${ }^{63}$, ha ido a la zaga en casi todos los sectores productivos, incluso en aquellos en los que la formación va ligada a la prevención de riesgos laborales y, por tanto, a la seguridad y salud de las personas trabajadoras. Lo que no quiere decir que esté absolutamente ausente en la acción sindical, sería injusto ser tan tajante, pero se echa en falta una línea concreta referida a la formación y cualificación. Repárese en lo llamativo de ejemplos como el francés donde desde la primera hora trabajada en el sector del empleo doméstico se tiene derecho a 58 horas de formación anuales gratuitas (financiadas con

\footnotetext{
${ }^{62}$ Es más, en octubre de 2013 se presentó una proposición no de ley para la ratificación del Convenio que fue aprobada por unanimidad en la Comisión de Empleo y Seguridad Social del Parlamento instando al Gobierno a reevaluar las razones para su no ratificación y plantearse, en consecuencia, la necesidad de su ratificación y la adopción de la legislación pertinente. A pesar de este acuerdo, del tiempo transcurrido y de que países del entorno (como Italia y Alemania) ya habían ratificado el Convenio, el Parlamento español no siguió trabajando en esta línea y ninguna otra medida fue adoptada en este sentido lo que es buena muestra del desinterés político por el tema. En definitiva, ni el Gobierno del PP, ni el del PSOE fruto de la exitosa moción de censura contra aquél, han considerado la importancia y oportunidad de ratificar de momento dicho convenio, alegando las recurrentes y burdas excusas expuestas líneas atrás, esto es, la complicada intervención en los hogares familiares, la dificultad de prevenir riesgos laborales en este sector y de introducir la prestación de desempleo en un momento difícil para las arcas de la Seguridad Social. Y ello pese a que, no podemos dejar de señalar, en este sentido, que hasta la Unión Europea ha instado a los Estados miembros de la Unión a que procedan a su ratificación. Para ello, la Comisión Europea presentó el 21 de marzo de 2013 una propuesta de Decisión del Consejo que autoriza a los Estados miembros a la ratificación del Convenio. Así, son diversas las instituciones sociales y los Grupos Parlamentarios en España que consideran la necesidad de iniciar los trámites necesarios para la ratificación del Convenio, especialmente tras la Decisión del Consejo de la UE de 28 de enero de 2014, publicada el 1 de febrero de 2014. De esta forma, el Consejo de la Unión ha seguido los pasos dados por la Comisión Europea y el Parlamento Europeo a favor del Convenio, que han instado también a los Estados miembros a ratificarlo y aplicarlo con urgencia. Esta posición de la UE es coherente con los contenidos de la Carta Social Europea y con los de la Carta de Derechos Fundamentales de la Unión, especialmente en lo que se refiere a "unas condiciones de trabajo justas y equitativas y a la protección social.

${ }^{63}$ Lo que choca frontalmente con iniciativas con la americana de 1937 impulsada por E. Roosevelt "Household Service Demostration Project" (HSDP) -Programa de Capacitación de Trabajadores del Hogardentro del Works Progress Administration (WPA) y que capacitó en las habilidades domésticas a 30.000 mujeres con gran éxito. Más detalles sobre esta iniciativa histórica en https://en.wikipedia.org/wiki/Household_Service_Demonstration_Project donde se contienen referencias bibliográficas interesantes pero de muy difícil acceso.
} 
cargo al plan de desarrollo de competencias ${ }^{64}$ ) y el amplísimo elenco de incentivos fiscales a las familias por la contratación de este personal (hasta el 50\% del gasto anual en servicio doméstico de las familias con el tope máximo de 7.500 euros/año). La experiencia francesa respecto de la lucha contra la informalidad a través de contratos tipo y "cheques de empleo y servicios" ${ }^{\circ 5}$ o "cesu" $u^{66 " ~(Q u i n t e r o, ~ 2020: 61 ~ y ~ s s .) ~ e s ~ u n a ~ b u e n a ~}$ práctica que comienza a ensayarse en otros países europeos (Italia con el libretto famiglia $^{67}$ ) y que es no solo interesante sino necesario implementar en España para empezar a cambiar las sinergias imperantes en el sector. El razonamiento es lógico: si las empresas/los empresarios cuentan con una serie de gastos deducibles que les permites llevar a cabo ciertas desgravaciones fiscales (con ciertos topes y limites) en sus impuestos, por qué no las familias que actúan como empleadores en estos casos?. Repárese en el hecho de que en nuestro país esto resulte hoy por hoy impensable bajo el pertinaz argumento de la sospecha de fraude que estas relaciones laborales suscitan (contratación entre familiares y retribución del trabajo doméstico ejercido por "amas de casa").

Esto es contradictorio, choca cuando tomamos conciencia de los beneficios que la formación incorpora, de forma casi automática, a la prestación de servicios o actividades. Y es que aumentan las oportunidades, mejoran las condiciones laborales, incrementan la satisfacción personal de las personas trabajadoras por lo que suponen de superación profesional. Cierto es que lo que la realidad arroja es un gran número de dificultades que se traducen tanto en lo referido a la oferta formativa como a la demanda. Por el lado de la oferta, es urgente que sindicatos, asociaciones y cooperativas tanto por el lado de los las personas trabajadoras como de los empleadores se impliquen en la mejora de la formación, si bien son constantes las quejas respecto de dificultades como las referidas a la difícil compatibilidad horaria de la oferta formativa con el trabajo doméstica, así como el desconocimiento de las familias empleadoras de los derechos de sus trabajadoras en este sentido. Por el lado de la demanda, el colectivo de trabajadoras domésticas, en sentido lato, necesita que la información le llegue a través de los agentes antedichos por tratarse de un colectivo que, como se ha adelantado, está aislado. Pero también, es preciso formular una oferta formativa en términos lo suficientemente atractivos para que decidan, desde su libertad individual, invertir tiempo en ello. Y esto, normalmente, lo hacen para salir del círculo vicioso del empleo doméstico -sector refugio ante contingencias como

\footnotetext{
${ }^{64}$ A partir del 1 de enero de 2019, el plan de desarrollo de competencias del Ministerio de Trabajo, Empleo e Inserción francés (plan de développement des compétences) reemplaza a su predecesor inmediato el plan de capacitación. Este plan permite a los empleados seguir acciones formativas por iniciativa de su empleador, frente a formaciones que pueden seguir por iniciativa propia a través de su cuenta de formación personal. El empresario tiene dos obligaciones en materia de formación profesional: adaptación al puesto de trabajo y retención de empleados; también puede proponer acciones que contribuyan al desarrollo de competencias (artículo L 6321-1 del código de trabajo francés). Más detalles en https://travailemploi.gouv.fr/formation-professionnelle/entreprise-et-formation/article/plan-de-developpement-descompetences

${ }^{65}$ Que simplifica las formalidades administrativas para los particulares hasta el punto de que no es necesario que se registren en el organismo recaudador de los cuotas a la Seguridad Social ni emitir nóminas, entre otros.

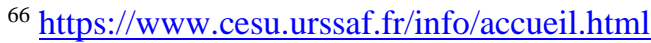

${ }^{67}$ Más información en https://www.inps.it/nuovoportaleinps/default.aspx?itemdir=51098.
} 
las crisis económicas y la escasez de empleo en otros sectores- y redirigirse hacia sectores próximos como el de cuidados a dependientes -sector de tránsito hacia otros considerados mejores-. Fundamental, por tanto, invertir recursos en campañas de sensibilización, de asesoramiento colectivo o personalizado, programas específicos de educación y capacitación, etc., incluso en aquellos destinados a hacer atractiva la implicación por parte de las familias (cheques, incentivos, etc.). La necesidad de intervención estatal de fomento o incentivo en este sentido es ineludible.

Antes de concluir, resulta fundamental, en la misma línea, hacer mención somera a la iniciativa concreta que supone el Proyecto Prodome ${ }^{68}$ que persigue la profesionalización del trabajo doméstico en consonancia con el Marco Europeo de Cualificaciones (MEC) y que propone un curriculum europeo común para el sector, en definitiva, una certificación europea. Una muestra del interés que el tema analizado tiene y del afán europeo por hacer algo en favor de tal objetivo. Y una apuesta decidida sustentada en el convencimiento de que a mayor formación y cualificación, mayor será la mejora tanto en la calidad de los servicios como en los derechos de las personas trabajadoras. Y la única receta eficaz para salir del círculo perverso informalidad-desprofesionalización-desprotección.

\section{Algunas ideas conclusivas.}

No quieren cerrarse estas líneas sin insistir en tres ideas fundamentales.

Primera, la imprescindible unificación terminológica pero también de concreción material del contenido de los servicios domésticos: ¿se trata de todas y cada una de las tareas y cuidados intrafamiliares que cubren las necesidades en materia de servicios personales de este sector emergente entendidas en sentido amplio, esto es, incluyendo la protección a la dependencia o no, eso es, solo de las que abarcan el elemento espacial del hogar?. Y ello es urgente porque de ello depende también el contenido de los planes formativos sean los que fueren. Es una obviedad decir que si precisamos de personal doméstico cualificado, va de suyo conocer previamente en qué competencias ha de formarse y con qué objetivos.

Segunda, siendo comprensible que el interés se haya centrado en el reconocimiento y la regulación del trabajo doméstico (labor encomiable de la OIT y tarea pendiente para España que tiene los deberes a medio hacer y debe cumplir de forma inminente con los compromisos internacionales vigentes), ha llegado el momento de, sin bajar la guardia respecto de lo ya logrado, avanzar en otras reivindicaciones como las formativas que mejorarían sustancialmente tanto el encaje de la oferta y la demanda en el sector como las condiciones de desarrollo de la actividad. Que las familias prefieran personal doméstico cualificado frente al no cualificado es obvio y que las trabajadoras valoren la oportunidad que el esfuerzo formativo les supone pero que puede repercutir positiva y directamente en sus condiciones laborales también. Entonces, hay que detectar dónde están las obstáculos. Solo algún ejemplo lanzado al vuelo: ¿es esta formación atractiva

\footnotetext{
${ }^{68}$ Más detalles al respecto disponibles en https://www.prodome.eu/es/los-resultados/
} 
para las jóvenes que abandonan sus estudios de forma prematura o solo es atractiva para las mujeres de cierta edad, sin estudios ni alternativa diferente de tener un empleo que le permita tener independencia económica y mantener a sus familias?, ¿dónde y de qué forma se organizan las prácticas obligatorias para concluir la formación señalada?, ¿podría articularse algún incentivo público que contribuyese a mejorar esta situación como los cheques servicio?. Muchas interrogantes sobre la mesa y mucho por hacer, lo que evidencia el gran reto social que ha de enfrentarse sin más dilación.

Tercera, las propias trabajadoras domésticas se están movilizando. Los sindicatos mayoritarios les están ayudando a crear una red internacional de organizaciones de estas trabajadoras que les dará la fuerza necesaria para hacer valer sus derechos. AL mismo tiempo, están haciendo aparición en escena pequeños sindicatos especializados (Sintrahocu o Sindihogar) que ponen de manifiesto el proceso de empoderamiento de estas trabajadoras y contribuyen a organizan estrategias eficaces cuando permiten identificar y abordar las necesidades específicas y la situación de las trabajadoras domésticas, a la vista de su necesidad de apoyo social, de servicios médicos y jurídicos, de lugares y horas estables de reuniones, y de estructuras que les permitan participar y organizarse; los sindicatos pueden tomar medidas para garantizar la voz y la representación de las empleadas domésticas en las confederaciones sindicales; pero, sobre todo, pueden promover la negociación colectiva en el sector, facilitar el proceso de registro de sindicatos específicos e identificar a empleadores con propósitos de negociación y establecer una plataforma de negociación colectiva como parte del marco jurídico vigente. Por último, las organizaciones de empleadores pueden y deben desempeñar un cometido crucial, organizando a empleadores e intermediarios, mientras nuestro modelo sea el que es y no se recurra a empresas intermediarias especializadas. En definitiva, ratificación del Convenio 189 OIT ya y derecho a la negociación colectiva como objetivo principal próximo e inminente. Ojalá podamos congratularnos en los próximos ¿meses? de este logro como acaba de hacerse con la aprobación del I convenio colectivo de fútbol femenino ${ }^{69}$.

\section{Bibliografía}

APARICIO RUIZ, Mª Germana, La profesionalización de los empleados al servicio del hogar familiar. Desde el contraste comparado de la normativa francesa, Eolas Ediciones, 2014.

CAÑABATE PEREZ, José, ““'Servir es distinto a trabajar”: Potestad del cabeza de familia vs. Protección social del servicio doméstico en la dictadura franquista", en GARCIA GONZALEZ, Guillermo, BONET ESTEVA, Margarita Y ESPUGNY I

\footnotetext{
69 Tras un largo proceso de negociación, el 18 de febrero de 2020 la Asociación de Clubes de Fútbol Femenino (ACFF), de un lado, y la Asociación Nacional de Futbolistas Españoles (AFE) y el Sindicato Futbolistas ON, de otro, han firmado el Convenio Colectivo del Fútbol Femenino (CCFF).
} 
TOMAS, M. ${ }^{\text {a }}$ Jesús (coord.), Relaciones laborales y empleados del hogar: reflexiones jurídicas, Dykinson, 2014.

EZQUERRA, Sandra, "Crisis de los cuidados y crisis sistémica: la reproducción como pilar de la economía llamada real”, Revista Investigaciones Feministas, vol. 2, 2011.

ABELLEIRA, Francisco Javier, "El trabajo al servicio del hogar: algunas propuestas desde el proyecto europeo PHS-QUALITY”, 10.07.2020. Disponible en https://forodelabos.blogspot.com/2020/07/el-trabajo-al-servicio-del-hogar.html

GRAU PINEDA, Carmen y DOMÍNGUEZ-MUJICA, Josefina, "La persistencia de mujeres inmigradas en el servicio doméstico en España en tiempos de recesión económica: datos para la reflexión", Revista de derecho migratorio y extranjería, no 40 , 2015.

GRAU PINEDA, Carmen, "El trabajo doméstico y de cuidados: La incidencia del Convenio 189 OIT sobre trabajo decente para las trabajadoras y los trabajadores domésticos", Revista Documentación Laboral, vol. 116, 2019.

GRAU PINEDA, Carmen, "De sirvientas a trabajadoras: la necesaria ratificación del Convenio 189 OIT sobre trabajo decente para las trabajadoras y los trabajadores domésticos”, Revista Jurídica de los Derechos Sociales Lex Social, vol. 9, nº 2, 2019.

GRAU PINEDA, Carmen, "Empleo doméstico y cuidadores informales: obstáculos para conciliar", en VVAA, Reflexiones sobre el empleo doméstico. De dónde venimos, dónde nos encontramos y hacia dónde vamos, Servicio Central de Publicaciones del Gobierno Vasco, 2020.

MIÑARRO YANINI, Margarita, "Formas esclavas de trabajo y servicio del hogar familiar: delimitación conceptual, problemática específica y propuestas", Relaciones Laborales, $\mathrm{n}^{\circ} 10,2014$.

NIETO ROJAS, Patricia, "El nuevo Sistema de Formación Profesional para el empleo (Ley 30/2015 y RD 694/2017) y el papel de los agentes sociales en su desarrollo", Revista de Información Laboral, ${ }^{\circ}$ 7, 2018.

OELZ, Martin, "El Convenio y la Recomendación de la OIT sobre las trabajadoras y los trabajadores domésticos. Una oportunidad para la justicia social”, Revista Internacional del Trabajo, vol. 133, nº 1, 2014.

PARELLA RUBIO, Sonia, "El trasvase de desigualdades de clase y etnia entre mujeres: los servicios de proximidad", Papers, no 60, 2000.

QUINTERO LIMA, Ma . Gema, "El trabajo de servicio doméstico como una realidad jurídica inevitable", Revista jurídica de los Derechos Sociales Lex Social, vol. 9, n 2, 2019.

QUINTERO LIMA, Ma . Gema, "El cheque servicio como elemento de gestión/control del trabajo doméstico: la necesaria definición conceptual”, en VVAA, Reflexiones sobre 
el empleo doméstico. De dónde venimos, dónde nos encontramos y hacia dónde vamos, Servicio Central de Publicaciones del Gobierno Vasco, 2020.

REQUENA MONTES, Óscar, Formación profesional continua y prestación de trabajo: El artículo 23 del Estatuto de los Trabajadores como mecanismo de conciliación, Tesis doctoral, 2019, disponible en acceso abierto en TESEO.

SALCEDO BELTRÁN, Carmen, "El trabajo doméstico en España: planteamientos y desafíos insoslayables frente a la "esclavitud moderna", Revista General de DTSS, Iustel, $n^{\circ} 55,2020$.

SANZ SÁEZ, Concha, La protección social de las empleadas de hogar. La desaparición del Régimen Especial de la seguridad Social y su integración en el Régimen General como Sistema Espacial: análisis actual y de futuro, Bomarzo, 2017.

SANZ SÁEZ, Concha, "La discriminación en contra de las empleadas de hogar como forma de manifestación de las discriminaciones múltiples", Revista de Derecho Social, $\mathrm{n}^{\circ} 83,2018$.

SANZ SÁEZ, Concha, "Derechos colectivos y empleadas del hogar: reformas jurídicas inaplazables para un trabajo decente del trabajo doméstico en España”, comunicación presentada y seleccionada respecto de la conversación II "Trabajo decente para todos" en el Congreso Interuniversitario OIT sobre el futuro del trabajo, Sevilla, 7-8 febrero 2019.

SANZ SÁEZ, Concha, "Profesionalización efectiva del servicio doméstico. Un trabajo pendiente", Revista jurídica de los Derechos Social Lex Social, vol. 9, nº 2/2019.

\section{Anexo informes y otros documentos}

FEPEM, Le secteur des particuliers employeurs et de l'emploi à domicile. Rapport sectoriel des branches, 2020, disponible en https://www.fepem.fr/wpcontent/uploads/Rapport-sectoriel-des-Branches_2020_VF.pdf

FUNDACIÓN PARA LA PREVENCIÓN DE RIESGOS LABORALES UGT, La Guía de buenas prácticas para la Prevención de Riesgos en la Ayuda a Domicilio, disponible en http://ergodep.ibv.org/component/docman/doc_download/29-.html,

CCOO, Trabajo doméstico y de cuidados para empleadores particulares, Proyecto por un trabajo digno, Vicesecretaria General de UGT, Departamento de Migraciones, Septiembre 2019.

CEDEFOP, "Quality assurance in the social care sector, research paper. The role of training", no 7, 2010, disponible en https://www.cedefop.europa.eu/en/publications-andresources/publications/5507

EFSI, PHS Industry Monitor, Statistical overview of the personal and household services sector in the European Union, April 2018, disponible en http://www.efsieurope.eu/fileadmin/MEDIA/publications/2018/PHS_Industry_monitor_April_2018.pdf 
OBSERVATORIO DE LAS OCUPACIONES, 2020 Mercado de Trabajo de las Mujeres, Estatal, Datos 2019, Madrid, BOE, 2020.

OBSERVATORIO DE LAS OCUPACIONES, Informe de prospección y detección de necesidades formativas 2019, Madrid, BOE, 2020.

OIT, Voz y representación de los trabajadores domésticos a través de la organización, Nota e información $\mathrm{n}^{\circ}$ 8, Servicio de Mercados Laborales Inclusivos, Relaciones Laborales y Condiciones de Trabajo (INWORK), Ginebra, 2016.

OIT, Perspectivas Social y del Empleo en el Mundo, Mujeres, 2018, OIT, Ginebra, 2018. OIT, Aplicación de las normas internacionales del trabajo, 2019, Informe de la Comisión de Expertos en Aplicación de Convenios y Recomendaciones, Informe III (Parte A), OIT, 2019.

SEPE, Repertorio Nacional de Certificados de Profesionalidad, Formación profesional para el empleo, Madrid, BOE, 2020.

UGT-PV, Cualificaciones profesionales del empleo doméstico, Valencia, UGT-PV, 2016. 